\title{
THE TRAGicomedY OF THE SURFERS' COMMONS
}

\author{
DANIEL NAZER*
}

\section{INTRODUCTION}

Ideally, the introduction to this article would contain two photos. One would be a photo of Lunada Bay. Lunada Bay is a rocky, horseshoe-shaped bay below a green park in the Palos Verdes neighbourhood of Los Angeles. It is a spectacular surf break, offering long and powerful rides. The other photograph would be of horrific injuries sustained by Nat Young, a former world surfing champion. Nat Young was severely beaten after a dispute that began as an argument over who had priority on a wave. These two images would help a non-surfer understand the stakes involved when surfers compete for waves. The waves themselves are an extraordinary resource lying at the centre of many surfers' lives. The high value many surfers place on surfing means that competition for crowded waves can evoke strong emotions. At its worst, this competition can escalate to serious assaults such as that suffered by Nat Young.

Surfing is no longer the idiosyncratic pursuit of a small counterculture. In fact, the popularity of surfing has exploded to the point where it is not only within the mainstream, it is big business. ${ }^{1}$ And while the number of surfers continues to increase,

\footnotetext{
" Law Clerk for Chief Judge William K. Sessions, III of the United States District Court for the District of Vermont. J.D. Yale Law School, 2004. I am grateful to Jeffrey Rachlinski, Robert Ellickson, Anthony Kronman, Oskar Liivak, Jason Byrne, Brian Fitzgerald and Carol Rose for comments and encouragement. I also thank Chris Brewster, Mike Sisson and Marcus Sanders for generously sharing documents and their time.

${ }^{1}$ For example, roughly 900,000 people (out of a population of approximately 20 million) surf regularly in Australia alone. See Brian Fitzgerald and Geoffrey Clark (eds), 'Law of the Surf Forum Number 2' (2002) 6 Southern Cross University Law Review 318, 324 (commentary by Melanie Mott) (hereinafter Surf Forum 2). Moreover, the United States surf equipment and apparel industry generates approxi-
} 
the number of surf breaks remains constant. Thus, crowding and conflict have increased. Publicity surrounding high profile incidents, such as the assault on Nat Young, have started to change the image of surfing. ${ }^{2}$ This new image of surfers has even reached Hollywood. Two recent movies, Blue Crush and Point Break, both included scenes of violence in the surf.

Despite the popularity of surfing and the high value that surfers place on waves, there is almost no state intervention in how waves are distributed among surfers. In the place of state intervention, surfers have developed a complicated set of norms or rules that govern behaviour in the surf and priority over the waves. This article considers the informal norms that govern surfing. These norms offer a rich and important case study in how a valuable resource can be shared between millions of people with no state intervention and relatively little conflict.

In Part II of this article, I explain the basics of surfing and review the resource management issues facing the surfing community. In Part III, I briefly review some of the literature about social norms and identify theoretical issues that my case study may help illuminate. Part IV examines the cooperative norms of surfing in detail. I find that a similar set of norms has emerged around the world. I suggest that these norms are directed toward efficiency and have allowed surfers to successfully manage their 'commons' despite the fact that the surf community as a whole is very large and is not close-knit.

In Part V, I turn to the darker side of surf culture, surfer localism. Localism involves an alternative set of norms that have arisen at certain surf breaks around the world. At it worst, localism seeks the outright exclusion, through violence, of nonlocal surfers. Part VI investigates responses to localism. These responses follow some of the strategies suggested by commentators on norms and the law. These include attempts to reinforce the cooperative norms of surfing, the enforcement of existing criminal law and an attempt to pass a law criminalising surfer localism.

mately $\$ 1.8$ billion dollars in revenue every year. See Duncan Campbell, 'Surf Wars Hit California', Guardian Unlimited, 12 March 2002,

<http:www.guardian.co.uk/elsewhere/journalist/story/0,7792,666039,00.html> at 24 October 2003.

2 See, for example, Paul McHugh, 'Surfing's Scary Wave: 'Localism' Intensifying at Ocean Breaks', The San Francisco Chronicle, 15 May 2003, C11; Duncan Campbell, 'California Police Step in to Stop Surf Wars', The Guardian, 10 June 2002, 14 


\section{SuRFING AND THE StRANGE ECONOMICS OF THE SURFERS' COMMONS}

\section{A So what is this surfing thing anyway?}

A grasp of the basics of surfing is essential before one can understand surfing's unwritten norms. Most of the norms of surfing are expressed in 'surf-speak'. Thus, this subpart contains an introduction to surfing and surfing terminology. This subpart should be skipped by any reader already familiar with the sport.

The first thing to note, is that surfers prefer to ride along the sheer face of a wave as it breaks behind them. By riding along the face of the wave, surfers reach greater speeds and harness more of the wave's power than simply riding the 'whitewater' or 'foam' of a wave that has already broken. A ride is usually more thrilling if the surfer is as close as possible to the breaking section (or 'curl') of the wave as he or she rides. The surfer closest to the breaking section of a wave is said to be on the 'inside'. 3

The spot at which a breaking wave can first be caught is called the 'peak' or 'takeoff zone'. A wave is known as a 'right' or a 'left' depending on the direction in which it is ridden from the peak. ${ }^{4}$ Some peaks offer both lefts and rights while others only break in a single direction. On a right breaking wave the surfer furthest to the left would be on the 'inside' and visa-versa. The group of surfers congregated in the area around the take-off zone or peak is often called the 'lineup'.

Surfing breaks can be divided into two further categories. These are point breaks and beach breaks. Point breaks, as the name suggests, break at points. Most point breaks break over a rock shelf or a reef. These breaks usually have a single peak with a stable position. Thus, the competition for waves tends to be far more intense and focused at point breaks because surfers must jostle for position within a small area. Beach breaks tend to have multiple and 'shifting' peaks. This means that surfers at beach beaks do not have to congregate in a single small area to compete for waves. Generally, point breaks offer better and longer rides than beach breaks. ${ }^{5}$

Sometimes a long 'section' of a wave will break all at once making it difficult for a surfer to ride along the face. Skilled surfers can deal with this problem by racing along the face and beating the section before it breaks or by moving down the face and around the front of the broken 'section'. This would be called 'making the section'.

\footnotetext{
${ }^{3}$ As will be explained in Part IV, a central norm of surfing is that the surfer on the inside has priority over a wave.

${ }^{4}$ The direction is determined from the perspective of looking from the wave toward the shore.

${ }^{5}$ For a more detailed description (and excellent diagrams) of the mechanics of surfing and surf breaks see Kent Pearson, Surfing Subcultures of Australia and New Zealand (1979) 134-40.
} 
Modern surfers ride a variety of different surf-craft. The differences between these craft (and the status of those who ride them) are relevant to understanding surfing norms. Most surfers ride standing up on fibreglass surfboards. These surfboards are divided into 'shortboards' and 'longboards'. Shortboards allow more manoeuvrability and are better suited to steep, powerful waves. Longboards are less manoeuvrable but are better suited to riding gently breaking (or 'mushy') waves. As they have more flotation and paddle speed, longboards also allow surfers to catch waves further out from shore. Thus, many surfers feel that longboards can offer an unfair advantage in the competition for waves. ${ }^{6}$

Other surfers ride bodyboards, surf-kayaks and wave-skis. Bodyboards are small foam boards and are usually ridden prone. Wave-skis and surf-kayaks have much greater paddle speed than all other surf craft. As was the case with longboarders, this natural advantage can create tension and conflict. ${ }^{7}$ Bodyboarders and wave-ski riders are often considered to have lower status than those who ride more traditional surfboards. $^{8}$

Some other terms of surf slang are worth knowing. Young surfers are often called 'grommets' or 'groms'. Incompetent surfers are derided as 'kooks'. Finally, don't forget that surfing is a lot of fun.

\section{B The Economics of the Surfers' Commons}

Hardin's classic fable of the 'tragedy of the commons' involved the over-grazing of a communal pasture. ${ }^{9}$ According to Hardin's story, livestock owners will always have an individual incentive to add to their herds even if the pressure caused by the additional animals will reduce the output of the community as a whole. ${ }^{10}$ This analysis can be generalised to other common resources, such as fisheries or national parks, because individuals will have incentives to overuse any resource open to the public. ${ }^{11}$ Moreover, individuals may not have an incentive to invest in an open resource if the public at large will snag the benefits of this investment. ${ }^{12}$ Thus, common resources may suffer from both overuse and under-investment leading to waste and inefficiency.

The surfers' commons is different from a fishery or a communal pasture, however. In fact, it is not even immediately obvious if there is such a thing as 'over-surfing'. Over-fishing today can lead to no fish tomorrow. Similarly, over-grazing can cause

\footnotetext{
${ }^{6}$ See Part IV(B)(1).

${ }^{7}$ See ibid.

${ }^{8}$ See Part V(B).

${ }^{9}$ See Garrett Hardin, 'The Tragedy of the Commons' (1968) 162 Science 1243, partially reprinted in Robert C Ellickson, Carol M Rose and Bruce A Ackerman (eds), Perspectives on Property Law ( $2^{\text {nd }}$ ed, 1995) 132.

${ }^{10}$ See ibid.

${ }^{11}$ Ibid 134

${ }^{12}$ See Carol Rose, 'The Comedy of the Commons: Custom, Commerce, and Inherently Public Property' (1986) 53 University of Chicago Law Review 711, 712.
} 
a pasture to be almost useless for future seasons. In contrast, today's surfers cannot change tomorrow's waves. There may be good surf tomorrow no matter how crowded the waves were last week. Thus, overcrowding of a surf break does not have the kind of long-term consequences caused by overuse of other resources.

Similarly, there is no threat of under-investment in the surfers' commons. Surfers are at the mercy of geography and meteorology. The size and direction of swell and the physical features of the coast facing the swell determine the number and quality of waves available. Thus, there is very little surfers can do to improve the quality of surf breaks. Artificial reefs have created a small number of new surf breaks. ${ }^{13}$ However, these breaks are very expensive and it is unlikely that the development of artificial breaks will play a significant role in surfing's future. ${ }^{14}$ Essentially, the number of waves available is independent of how the resource is managed.

So, how can surfers overuse or under-invest in their commons? The key to answering this question is the premise that the most efficient way to manage a surf break is to ensure that as many waves as possible are surfed and that each of these waves is surfed by a single surfer. Obviously, any wave that goes unsurfed is wasted. Also, only one person should ride each wave. It is far less enjoyable to share a wave as the presence of another surfer limits the ability to manoeuvre. ${ }^{15}$ More importantly, the risk of collision makes sharing waves unsafe. Thus, there is a consensus among surfers that only one person should ride each wave. In fact, this is probably surfing's most universal norm. ${ }^{16}$ Overall, surfers will under-use their commons whenever they waste an available wave and they will overuse their commons whenever more than one surfer rides a wave.

Surfing can be considered a kind of mixed-motive game. Mixed-motive games are games in which the players have a common interest in coordination even though they have some conflicting interests. ${ }^{17}$ In a simple coordination game the players have an interest in coordinating their behaviour. ${ }^{18}$ For example, drivers have an interest in coordinating which side of the road to drive on. Drivers may not care which side of the road is chosen as long as all drivers coordinate and choose the same side. Mixed-motive games add an element of conflict to a coordination game.

The Hawk-Dove game is an example of a mixed-motive game that is useful for modelling the choices faced by surfers. McAdams presents the following example of a Hawk-Dove game. In the game the most desirable outcome comes from

\footnotetext{
${ }^{13}$ See Nat Young, 'Surf Rage' in Nat Young (ed), Surf Rage (2000) 208, 212-214.

${ }^{14}$ The artificial reef at Cottestloe in Australia cost approximately US\$1 million. See ibid. Moreover, the artificial reef (which happens to be the closest surf break to my Australian home) rarely breaks well and local surfers generally consider it to be a failure.

${ }^{15}$ Midget Farrelly, a world surfing champion in the 1960s, wrote 'if there is another fellow on the wave I have to think about five things - myself, the board, the wave, him and his board. . . . [i]t just clutters things up and is no fun at all.' Midget Farrelly, The Surfing Life (1965) 17-18.

${ }^{16}$ See Part IV(A)(1).

${ }^{17}$ See Richard H McAdams, 'A Focal Point Theory of Expressive Law' (2000) 86 Virginia Law Review $1649,1672-76$

${ }^{18}$ Ibid 1654-58.
} 
playing Hawk against Dove (here providing a utility of 2), followed by playing Dove against Dove (1), playing Dove against Hawk (0), and playing Hawk against Hawk (-2). ${ }^{19}$ Figure 1 illustrates this game.

\begin{tabular}{|c|c|c|}
\hline & Dove & Hawk \\
\hline Dove & 1,1 & 0,2 \\
\hline Hawk & 2,0 & $-2,-2$ \\
\hline
\end{tabular}

Figure 1

Surfing can be modelled as a Hawk-Dove game. ${ }^{20}$ Suppose two surfers are in position to catch a wave. Each has the option of catching the wave or letting it pass. We can assume that if both surfers catch the wave then they risk collision and injury and thus will receive a negative payoff (here providing utility of -4 ). If both surfers let the wave pass then neither will receive any payoff. If one surfer catches the wave while the other lets it pass then the successful surfer gets a positive payoff (here 3 ). Figure 2 illustrates this game. ${ }^{21}$

\begin{tabular}{|c|c|c|}
\hline & Pass & Catch \\
\hline Pass & 0,0 & 0,3 \\
\hline Catch & 3,0 & $-4,-4$ \\
\hline
\end{tabular}

Figure 2

This payoff matrix gives the players an incentive to coordinate to ensure that they do not both play Hawk and catch the wave. Moreover, because the players receive no payoff from passing, the most efficient strategy is for one player to catch the wave while the other passes. Thus, surfers will benefit from norms that enable them to determine when they should pass and when they should catch the wave. In Part IV, I discuss the central drop-in norm of surfing. This norm accomplishes this exact task.

\footnotetext{
${ }^{19} \operatorname{Ibid} 1674$.

${ }^{20}$ Feedback from Jeffrey Rachlinsky convinced me that surfing is better modelled as a Hawk-Dove game than as a prisoner's dilemma game. Surfing is more like a Hawk-Dove game because of the common interest in coordination (to ensure one surfer per wave).

${ }^{21}$ Note that there is no dominant strategy in a Hawk-Dove game like this. In a prisoner's dilemma game the dominant strategy for both players is to defect. In a Hawk-Dove game, however, there is no dominant strategy as it is better to play Dove (pass) against Hawk (catch) but it is better to play Hawk (catch) against Dove (pass).
} 
Although Figure 2 is a good model for surfing, it is a tremendous simplification. Some of the more obvious complications are worth discussing. First, not every surfer's payoff schedule will be the same. For example, a particularly skilled surfer may be more capable of avoiding a wipe-out or collision while sharing a wave. ${ }^{22}$ Thus, some surfers may have a positive payoff from 'Catch' even when the other surfer catches the wave. Figure 3 illustrates a game involving such a surfer.

\begin{tabular}{|c|c|c|}
\hline & Pass & Catch \\
\hline Pass & 0,0 & 0,3 \\
\hline Catch & 3,0 & $1,-2$ \\
\hline
\end{tabular}

Figure 3

In the game illustrated by Figure 3, 'Catch' is the dominant strategy for one of the surfers. Thus, in a one-shot game this surfer will always catch the wave even though this can lead to a negative global utility. Sanctions offer a solution to this problem. Serious sanctions for playing 'Catch' against 'Catch' could ensure that this is no longer a dominant strategy for some surfers. ${ }^{23}$

There are two other obvious complications. First, surfing usually involves more than two 'players'. Thus, any norm that determines which surfer should play 'Catch' may need to designate a single surfer out of a large group. Second, the surfing game is an iterated game with multiple rounds. If surfing were a two-player game then multiple iterations could provide a simple solution of taking turns. The solution of taking turns becomes more difficult to administer with a larger number of players, however.

Finally, it is worth noting that severe overcrowding can lead to inefficiencies even if every surfer tries to observe cooperative norms. This is because surfers who are simply paddling around can still get in the way of the surfer actually riding a wave and ruin the ride or cause a dangerous collision. ${ }^{24}$ Obviously, there is some upper limit to how many surfers can surf a break safely. ${ }^{25}$ If thousands of surfers tried to surf at a single break there simply wouldn't be room to move around. Thus, surfers may need to develop norms dealing specifically with overcrowding.

\footnotetext{
${ }^{22}$ This will be especially likely on gently breaking waves with wide shoulders.

${ }^{23}$ Surfers' sanctioning behaviour is discussed in Part IV(C).

${ }^{24}$ Surfers' norms relating to avoiding collisions are discussed at Part IV(A).

${ }^{25}$ See Part V(G)(3).
} 


\section{SOCIAL NORMS}

In recent years, legal researchers have devoted a lot of attention to the role of social norms and the relationship between norms and law. ${ }^{26}$ This literature includes a diverse sample of case studies as well as more theoretical work. There are case studies of the norms among ranchers, the norms of feuding and revenge, norms within the diamond industry, norms among scientists and norms among sumo wrestlers in Japan. ${ }^{27}$ This article is intended to add another case study to the literature. It is hoped that this case study will both be interesting on its own and will provide a few helpful insights for the more abstract questions about social norms.

\section{A Definitions and theoretical issues}

The literature discussing social norms is diffuse and researchers have not settled on a single definition of 'social norm'. ${ }^{28}$ Nevertheless, many common threads emerge. First, social norms are more than just regularities in behaviour. Social norms are usually considered to be obligations in some sense. Robert Cooter provides the following useful illustration: ' $[\mathrm{M}] \mathrm{en}$ take off their hats when they enter a furnace room or a church. Taking off your hat to escape the heat is different from taking off your hat to satisfy an obligation. The former is a regularity and the latter is a norm. $^{29}$

Perhaps the best way to distinguish norms from mere regularities is to distinguish norms on the basis of sanctions. ${ }^{30}$ On this view, a norm is more than a regularity because the violation of a norm generates a negative affect among those who know about the norm and this may be accompanied by sanctions. For example, if we see someone wearing a hat in a hot room we will simply wonder why he doesn't make

\footnotetext{
${ }^{26}$ See Andrew J Chappel, 'Bringing Cultural Practice into Law: Ritual and Social Norms Jurisprudence' (2003) 43 Santa Clara Law Review 389, 389 n1 (citing numerous law review articles and books published since 1990 that discuss social norms); Robert C Ellickson, 'Law and Economics Discovers Social Norms' (1998) 27 Journal of Legal Studies 537, 543 ('[I]n the mid-1990s norms became one of the hottest topics in the legal academy.').

${ }^{27}$ See Luc Faucher, Ron Mallon, Daniel Nazer, Shaun Nichols, Aaron Ruby, Stephen Stich and Jonathon Weinberg, 'The Baby in the Lab-coat; Why Child Development is an Inadequate Model for Understanding the Development of Science' in Peter Carruthers, Stephen Stich and Michael Siegal (eds), The Cognitive Basis of Science (2002) 335, 343-48 (discussing science as a norm-governed activity); Arti Kaur Rai, 'Regulating Scientific Research: Intellectual Property Rights and the Norms of Science' (1999) 94 Northwestern University Law Review 77; Mark West, 'Legal Rules and Social Norms in Japan's Secret World of Sumo' (1997) 26 Journal of Legal Studies 165; Lisa Bernstein, 'Opting Out of the Legal System: Extralegal Contractual Relations in the Diamond Industry' (1992) 21 Journal of Legal Studies 115; Robert C Ellickson, Order Without Law: How Neighbors Settle Disputes (1991) 1-123 (presenting a detailed case study of social norms among ranchers and other neighbours in California's Shasta County); Jon Elster, 'Norms of Revenge' (1990) 100 Ethics 862.

${ }^{28}$ See Ellickson, above n 26, 549 ('The waters are so muddy that many writers on norms feel compelled to start by proffering their own definition of norm.').

${ }^{29}$ Robert D Cooter, 'Decentralised Law for a Complex Economy: The Structural Approach to Adjudicating the New Law Merchant' (1996) 144 University of Pennsylvania Law Review 1643, 1656 (1996) (footnote omitted).

${ }^{30}$ This is essentially the approach followed in Ellickson, above n 27, 123-32.
} 
himself more comfortable. In contrast, if the same man wears a hat in church he will annoy onlookers and may encounter disapproving looks, muttering or a pointed request to remove his hat.

A variety of actors can administer sanctions. We can distinguish first, second and third-party sanctions. ${ }^{31}$ First-party sanctions are administered by the primary actor himself or herself. Second-party sanctions are administered by the person acted upon and third-party sanctions are administered by other individuals or groups. For example, if a person cuts in line he may feel personal guilt (a first-party sanction), be yelled at by someone who had priority in the line (a second-party sanction) or be the subject of negative gossip by his peer group (a third-party sanction).

Norms are more powerful than individual self-help. This is because much of the enforcement power of norms comes from first and third-party sanctions. A norm violation 'typically provokes negative affect and an inclination to sanction or punish [even] among members of the community who are not directly involved or harmed. ${ }^{32}$ This suggests that the enforcement of norms is not always based on a selfish individual motivation. Moreover, people can internalize norms and choose to abide by them even when external sanctions are unlikely. ${ }^{33}$ Thus, a norm can be successful even when second and third-party sanctions are rare. Nevertheless, a norm violation will authorise third-party sanctions (that may be as mild as disapproving looks).

The theoretical work on norms and law has addressed a number of issues such as the best way to define social norms, the origins of social norms, the efficiency of social norms and how social norms can be changed. ${ }^{34}$ This case study will address a few of these issues. In particular, I will look at whether surfing norms are efficient, ${ }^{35}$ the rationality of sanctioning behaviour, ${ }^{36}$ and how norms can be deliberately manipulated to influence public policy. ${ }^{37}$

\footnotetext{
${ }^{31}$ Ibid 131

${ }^{32}$ Faucher, above n 27, 345.

${ }^{33}$ See generally, Amitai Etzioni, 'Social Norms: Internalization, Persuasion, and History' (2000) 34 Law and Society Review 157 (arguing that most of the power of social norms comes from internalisation and first-party based incentives).

${ }^{34}$ See, for example, Ellickson, above n 27, 124-286 (developing a taxonomy of social norms and arguing that many social norms are efficient); Robert Cooter, 'The Normative Failure Theory of Law' (1997) 82 Cornell Law Review 947 (discussing formation and change of social norms); Richard H McAdams, 'The Origin, Development and Regulation of Norms' (1997) 96 Michigan Law Review 338; Eric A Posner, 'Symbols, Signals, and Social Norms in Politics and the Law' (1998) 27 Journal of Legal Studies 765 (discussing how norms can be changed)

${ }^{35}$ See Part IV(D)

${ }^{36}$ See Part V(G)(2).

${ }^{37}$ See Part VI(A).
} 


\section{B A methodological aside}

Bob Ellickson is not a rancher and Mark West is not a sumo wrestler. I am a surfer, however. Thus, my own experiences are part of the source material for this article. Thankfully, I was also able to draw upon a rich variety of primary material about surfing norms. These include published interviews with surfers, the surfing community's own educational materials about surf etiquette, reported cases and sociological research about surfers. I also conducted a small number of interviews myself. Thus, I feel confident that my factual conclusions about surfing norms are based on a sufficiently broad range of evidence.

My normative conclusions raise a more serious methodological concern, however. Much of this article discusses the 'problem' of localism and attempted responses to it. $^{38}$ Some surfers do not believe that localism is a problem. ${ }^{39}$ Other surfers, while accepting that localism has negative aspects, believe that localism also has significant virtues. ${ }^{40}$ I believe that anything more forceful than the mildest form of localism $^{41}$ is pernicious. I will attempt to justify this view, but the reader should note that I have had some negative personal experiences with localism. Thus, I cannot claim to be a fully unbiased observer.

\section{Surfing Norms (A Comedy OF the Commons?) $)^{42}$}

This part looks at the cooperative norms of surfing. Surfers use a variety of terms to describe these norms. These include the 'Surfriders Code' ${ }^{43}$, the 'Surfers Code of Ethics' 44 and the 'Tribal Law of Surfing'. ${ }^{45}$ These norms have been a massive success story and have allowed many millions of people to share a valued resource with almost no state intervention and relatively little serious conflict. Surfing norms are usually unwritten. ${ }^{46}$ Some 'codifications' of surfing norms are available,

\footnotetext{
${ }^{38}$ See Parts V-VI.

${ }^{39}$ See, for example, Fred Pawle, 'The Australian Way', in Nat Young (ed) Surf Rage (2000) 85, 85.

${ }^{40}$ See, for example, Steve Barilotti, Localism Works (2003)

$<$ http://surfermag.com/magazine/archivedissues/locismwrks> at 28 April 2004.

${ }^{41}$ I describe 'mild localism' in Part V(A).

${ }^{42}$ I use the term 'Comedy of the Commons' in a sense borrowed from Carol Rose. Rose uses 'comedy' in 'the classical sense of a story with a happy outcome.' Rose, above n 12, 723. Thus, a 'comedy of the commons' is a story of a successfully managed commons.

${ }^{43}$ See Brian Fitzgerald and Geoffrey Clark (eds), 'Law of the Surf Forum' (2001) 5 Southern Cross University Law Review 228, 242 (showing a reproduction of a poster created by the Surfrider Foundation of Australia) (hereinafter Surf Forum 1).

${ }^{44}$ See NEsurf, Surfers Code of Ethics <http://www.nesurf.com/Articles/Ettiquette/etiquette.html> (last visited 17 October 2003) (hereinafter Surfers Code of Ethics) (NEsurf is a website serving the surf community of the north-eastern United States. Visitors are encouraged to print out the Surfers Code of Ethics and 'distribute it to as many people as you can.' Ibid).

${ }^{45}$ See Nat Young (ed) Surf Rage (2000) 8 (reproducing a plaque which is fixed near a surf break in Margaret River in Western Australia).

${ }^{46}$ See Surf Forum 2, above n 1, 349-50 (commentary by Brian Fitzgerald \& Geoffrey Clark) (noting that surf norms 'have been passed down through generations of surfers, mentors and/or gurus').
} 
however. ${ }^{47}$ These codifications show that basic surfing norms are almost identical around the world.

In this Part, I discuss the different layers of surfing norms. First, I discuss the more precise norms of surfing. These norms apply at almost all surf breaks. As Yale Law School's surfing Dean told me, these norms comprise the 'universal implied jurisprudence' of surfing. ${ }^{48}$ Second, I discuss some of the more variable and imprecise surfing norms. These include norms governing whether surfers should try to share waves equitably. Third, I focus on the issue of sanctions in the surf. Finally, I consider how my findings relate to theoretical concerns about social norms.

\section{A Rules of the road}

This subpart reviews the more clear-cut surfing norms. These norms are the general 'rules of the road' that apply at almost all surf breaks. These norms can be challenging to apply as they can involve split second judgments about many factors such as other surfers' intentions and about how a wave is going to break. Even though these rules can be difficult to apply, however, they still give fairly determinate answers as to how surfers should behave. Thus, if surfers are given the same information about a situation they will usually agree on how to apply these norms. I begin by discussing the most essential of these norms.

\section{$1 \quad$ Three fundamental norms}

Of the concrete norms of surfing, three in particular stand out as fundamental and universal. These norms govern which surfer has priority over a wave and safety issues. 'The most basic rule is that one surfer should not 'drop in' on another surfer. ${ }^{49}$ A surfer 'drops in' when he or she takes off on a wave where another surfer has priority. A surfer has priority if he or she is already riding the wave. ${ }^{50}$ If no surfer is yet riding the wave, the surfer further on the inside (closest to the breaking section of the wave) has the right of way. ${ }^{51}$ The rule against dropping in implies an obligation to monitor the position of other surfers. ${ }^{52}$ Thus, whenever a surfer attempts to catch a wave he or she has an obligation to ensure that there is no one already riding the wave and no one else is about to catch the wave on the inside. The rule against dropping in 'appears to be a cross cultural universal., 53

At least two other basic and universal norms appear in the codifications of surf etiquette. These are the 'paddle-wide' norm and the 'don't-throw-your-board'

\footnotetext{
${ }^{47}$ See sources cited above n 44-46; Mark Jury, Surfing in Southern Africa (1989) 116.

${ }^{48}$ Dean Anthony Kronman, Personal communication February 2004 (Dean Kronman, who grew up in Southern California, is a lifelong surfer).

${ }^{49}$ Surf Forum 2, above n 1, 350 (commentary by Brian Fitzgerald \& Geoffrey Clark).

${ }^{50}$ See, for example, Surfers Code of Ethics, above n 44.

${ }^{51}$ See, for example, ibid.

${ }^{52}$ See, for example, Jury, above n 47, 116.

${ }^{53}$ Pearson, above n 5, 141.
} 
norm. ${ }^{54}$ Surfers are encouraged to paddle away from the part of the wave most likely to be ridden by others. This helps prevent collisions. At point breaks, this means moving further away from land and paddling around the area where waves break. 'Paddling wide' can be more difficult at beach breaks because the location of the breaking waves can shift. At beaches, surfers are encouraged to find the rips (where the water is sucked back out to sea) rather than paddling back out through the breaking waves. ${ }^{55}$

Finally, surfers are encouraged not to let go of their surfboards if they are forced to pass through a broken wave. ${ }^{56}$ Most surfers are attached to their surfboards via a leg-rope. Thus, it is often easier to dive underneath a broken wave by letting go of the board, swimming underneath the wave and then retrieving the board. The alternative is to 'duck-dive' which involves holding onto the board and pushing it under the wave. Duck-diving under large waves is a challenging skill to master. Nevertheless, surfers are expected to duck-dive because a loose board creates a hazard to any surfer closer toward the shore. ${ }^{57}$ Surfers generally only benefit others when they attempt a challenging duck-dive instead of 'throwing' their board. This means that cooperation here only has a pay-off if other surfers reciprocate.

It is worth noting that even these fundamental norms of surfing reveal some layering of norms. For example, the central norm governing priority over a wave (the drop-in rule) is itself an instantiation of the even more fundamental norm directing that only one surfer should ride each wave. The one-surfer-per-wave norm is so deeply ingrained in surfing culture that this norm does not even appear in attempted 'codifications' of the rules of surfing. ${ }^{58}$ The norm is simply implicit in the drop-in rule.

\section{$2 \quad$ Additional concrete norms}

Surfers' obligations can extend beyond following the basic rules outlined above. There are some additional 'rules of the road' governing issues such as how to paddle out and signalling one's intention to other surfers. In this subpart, I examine these additional concrete norms.

One only has to review Surfline's Bill of Rights and Lefts to appreciate the complexity of surf norms. ${ }^{59}$ This document is intended to educate surfers about surf

\footnotetext{
${ }_{55}^{54}$ See, for example, Young, above n 45 (reproducing the 'Tribal Law of Surfing' plaque).

${ }^{55}$ See ibid.

${ }^{56}$ See, for example, ibid; Surfers Code of Ethics, above n 44 (noting in capital letters that you should 'NEVER THROW YOUR BOARD').

${ }^{57}$ See Surfline, Bill of Rights and Lefts <http://www.surfline.com/surfology/surfology_borl_index.cfm> at 28 April 2004 (noting that if you let go of your board 'any surfer within 10 or more yards, particularly behind you, is immediately placed in serious danger') (hereinafter Bill of Rights).

${ }^{58}$ See sources cited above $\mathrm{n}$ 44-46.

${ }^{59}$ See Bill of Rights, above n 57. Surfline is one of the world's most popular surfing websites averaging over one million unique hits per month. See Telephone interview with Marcus Sanders (8 March 2004) (on file with author) (Marcus Sanders is an editor at Surfline).
} 
norms and to help them know what to expect while surfing. ${ }^{60}$ While the 'Bill' only provides ten general rules, the details of each rule are explained with at least a full page of text creating a large document.

Thus, before reviewing more norms, it is worth asking the following question: can surfers really be expected to know and follow such a detailed set of rules? This question is pertinent because empirical evidence suggests that ordinary surfers are unlikely to articulate surfing norms in such detail. Stephen Kuhn asked Australian surfers to name five 'laws of the surf.' ${ }^{, 61}$ Kuhn found that most surfers could only name two or three 'laws' ${ }^{62}$ In a previous work, I endorsed the view that norms must be common knowledge in the sense that ' $[\mathrm{m}]$ ore or less everyone knows them and more or less everyone knows that everyone knows them. ${ }^{63}$ This view of norms, when combined with the results of Kuhn's study, suggests that any complex picture of surf norms (such as that found in Surfline's Bill of Rights and Lefts) must be inaccurate because its complexity is inconsistent with the simple picture presented by individual surfers.

I think this conclusion can be avoided by noting that '[a] rule can exist even though the people influenced by the rule are unable to articulate it in an aspirational statement. ${ }^{64}$ In fact, Kuhn's study supports this. Although each surfer tended to name few norms, Kuhn's subjects identified a large number of total norms. ${ }^{65}$ Kuhn suggests that 'from the responses, there appears to be about 15 or 20 rules of the surf., 66 Thus, the complex picture of surfing norms seems to be accurate. So, having justified the claim that surfing norms are complex, let's turn to the norms themselves. I shall review the following five concrete norms:

1. Give way to the person paddling out;

2. Do not engage in 'pre-emptive paddling';

3. Indicate your intentions to other surfers;

4. $\quad$ Ride any wave offered to you by other surfers;

5. Pick the right surf spot for your ability.

These norms complement the norms outlined in the preceding subpart.

The first of these additional norms requires the surfer riding a wave to give way to a surfer paddling out. ${ }^{67}$ The surfer riding the wave generally has more speed and manoeuvrability than the surfer lying prone on his or her board. Thus, if a collision is imminent the surfer on the wave is better able to avoid it. ${ }^{68}$ This rule is not

\footnotetext{
${ }^{60}$ See Telephone interview with Marcus Sanders (8 March 2004).

${ }^{61}$ Surf Forum 2, above n 1, 334 (commentary by Stephen Kuhn).

${ }^{62}$ See ibid.

${ }^{63}$ Faucher, above n 27, 345

${ }^{64}$ Ellickson, above n 27,130

${ }^{65}$ See Surf Forum 2, above n 1, 334-335 (commentary by Stephen Kuhn).

${ }^{66}$ Ibid 334.

${ }^{67}$ See Surf Forum 2, above n 1335 (commentary by Stephen Kuhn) (appearing as rule 5 of Kuhn's list).

${ }^{68}$ This rule can be compared to the norm that motor craft give way to sailing craft.
} 
necessarily inconsistent with the 'paddle-wide' rule outlined above. The paddling surfer is still obliged to try to avoid creating the possibility of a collision in the first place. If the paddling surfer fails in this task (because of the changeability of surf conditions, this can happen to the most careful surfer) then the surfer on the wave should avoid the paddling surfer. Nevertheless, a surfer should not ignore the paddle-wide rule because 'not all surfers in the water have the skill or inclination to avoid your prone board and body floating up into their paths. ${ }^{69}$

The rule against pre-emptive paddling illustrates the potential complexity of the drop-in rule. Suppose surfer A is riding a wave that is about to have a large section break at once. If the breaking section is large enough, A will almost certainly wipe out or get caught behind the section. This means that surfer B, sitting further along, can take off on the wave without dropping in on A. Whether B has dropped in will depend on whether A could have 'made the section' and continued along the face of the wave past B. This is determined by two factors. These factors are: (1) the size of the breaking section; and (2) A's skill. Thus, B is faced with an instantaneous and complicated task of judging whether $\mathrm{A}$ is likely to make the section. As part of this task involves judging A's ability, an incorrect decision (at least from A's perspective) is especially likely to cause resentment.

This situation is made even more complicated (if that seemed possible) by the fact that $\mathrm{B}$ can ruin things for A simply by paddling for the wave. This gives us preemptive paddling:

Surfer A is hurtling down the line from a long way back, and Surfer B figuring A won't make the section - begins to paddle into the wave. As A approaches, B pulls back; but his paddling efforts cause the wave to crumble and break in front of A. Result, A wipes out or is caught behind, and the wave peels off unridden. Bad move, B. ${ }^{70}$

Pre-emptive paddling is a common problem. ${ }^{71}$ Moreover, as avoiding it requires instant and difficult judgment, it can easily become a topic of dispute among surfers. $^{72}$

Surfers are obliged to make their intentions clear. This usually involves 'calling' out whether one intends to catch a wave and which direction one intends to ride it. ${ }^{73}$ Often a wave can be ridden either right or left and this makes calling especially

\footnotetext{
${ }^{69}$ Bill of Rights, above n 57 (discussing rule 3 'When paddling out, stay out of the way of riders on the waves').

${ }^{70}$ Ibid (discussing rule 4 'Learn to take turns').

${ }^{71}$ See ibid.

${ }^{72}$ I once had a heated argument with a good friend about whether I had engaged in pre-emptive paddling and ruined a good wave for him (I hadn't, of course).

${ }^{73}$ See, for example, Surfers Code of Ethics, above n 44 (suggesting '[c]all out 'left' or 'right' as appropriate, communicate'); Young, above n 45 (reproducing the 'Tribal Law of Surfing' plaque) (The plaque includes a diagram with two surfers riding a single wave in opposite directions with one surfer calling 'left' and the other calling 'right'.)
} 
important. For example, surfer A may have priority over B if A intends to go right. If A goes left, however, then B is free to ride the wave right. B will be annoyed if he defers to A's priority and then watches A head off in the other direction. If A had communicated his intention, then B could also have ridden the wave. Similarly, if a surfer with priority decides to abandon a wave he or she should yell out something like 'go for it!' to the other surfers so they know the wave is available.

The preceding discussion may make it seem that A and B could both have priority under the drop-in rule if they intend to ride toward the other surfer (as they would both be 'inside' from the perspective of their chosen direction). In this situation the surfer closest to the peak always has priority and can choose his or her direction. ${ }^{74}$ This provides another example of the potential complexity of surfing's central dropin norm.

The fourth norm is a corollary of the norm favouring communication. If surfers are informally sharing waves then a surfer may find himself 'called on' to a wave by other surfers. Essentially, this means the group has allocated this wave to that surfer. This is most likely to occur at breaks with established groups of locals but it could occur at any break. In this situation, a surfer would be well advised to try to ride the wave, no matter how challenging. Otherwise, the surfer is likely to find his or her status decline and have his or her share of the waves dry up. As surf journalist DC Green observes: '[N]ever, ever pull back when called into a wave. . . . [b]etter by far to plunge over the falls and get totally smashed than be condemned forevermore by the locals .... ${ }^{75}$

The final norm encourages surfers to be sensible about where they surf. The norm states that surfers should surf at breaks commensurate with their ability. ${ }^{76}$ A beginner can endanger himself or others by paddling out into large or otherwise challenging waves. A beginner is likely to encounter resentment if he or she surfs at a crowded and challenging break because the beginner is more likely to violate (intentionally or not) the rules of the road. ${ }^{77}$ Thus, this norm is a meta-norm telling surfers to choose breaks where they will have enough skill to observe the other norms of surfing.

\footnotetext{
${ }^{74}$ See Surfers Code of Ethics, above n 44 (noting that a surfer is 'not entitled to cross under the peak to the [other] shoulder [if it is] already occupied').

${ }^{75}$ DC Green, 'Terror in the Saltbush', in Nat Young (ed), Surf Rage (2000) 178, 194. On a personal note, I was once called onto a large set wave by locals at a break near the town of Denmark in Western Australia. Years later, I still feel embarrassed as I recall their groans after I hesitated, pulled back and let what was probably the day's largest wave pass by unridden.

${ }^{76}$ See Bill of Rights, above n 57 (stating that '[i]t's important for all of us to realize that by charging into a lineup for which we're not suited, we're likely to be frustrated and to disrupt others' surfing enjoyment.')

${ }^{77}$ A beginner is more likely to violate the 'don't throw your board' norm or the paddle wide norm, for example. Observing these norms at a challenging break requires considerable skill and paddling strength.
} 


\section{B Imprecise and abstract norms}

Surfers will generally agree on how to apply the norms discussed so far. Thus, any surfer arriving at a new break will know that, at a minimum, he or she has to observe those norms. Nevertheless, any surfer arriving at a new break will still feel uncertainty about the local norms. For example, the visitor might encounter varying norms governing the balance between sharing and aggressive competition for waves. Other norms relate to the phenomenon of 'localism'. These norms regulate the relationship between locals and visiting surfers. Surfers also promote respectbased norms that seem so abstract that they do not direct any particular conduct.

Localism norms are very important to visitors because locals may even use violence to intimidate visiting surfers. ${ }^{78}$ Localism is discussed separately in Part V. This subpart focuses on the variation in the competitiveness of surf breaks and on abstract surfing norms.

\section{$1 \quad$ Norms governing competition and sharing}

The following norms regulate competition and sharing and can be found at some surf breaks and in some codifications of surfing etiquette:

1. Share waves and take turns;

2. Do not 'snake';

3. Choose a break that suits your 'attitude';

4. Do not abuse your surfing advantages.

The first norm simply encourages sharing. This norm states that surfers should not 'hog' the waves (take more than one's fair share). ${ }^{79}$ This is a norm that is hard to enforce. If a surfer is skilled at competing for waves he or she can usually manoeuvre inside other surfers and get priority over a wave even if the other surfers have been waiting longer. Depending on the break, this can breed resentment and could eventually lead to dropping in or other conflict. At some breaks intense competition for waves may be tolerated. At other breaks, an informal sharing regime can emerge. ${ }^{80}$ This makes it very difficult to judge when a surfer violates a sharing norm. Marcus Sanders, an editor at Surfline, said 'the hard thing is knowing when someone is taking too much - a drop in is a drop in - but when someone's just ridden 14 waves then maybe they don't have priority any more. ${ }^{, 81}$

The variation among surfers' attitudes to sharing can be seen in the two different versions of their prohibition of 'snaking'. One definition of snaking holds that snaking is deliberately obstructing another surfer as he or she paddles for a wave. Another definition of snaking suggests that snaking is a violation of a sharing norm.

\footnotetext{
${ }_{78}^{78}$ Anthony Kronman, Personal communication February 2004.

${ }^{79}$ See Surf Forum 2, above n 1, 335 (commentary by Stephen Kuhn) (appearing as rule 14 on Kuhn's list); Bill of Rights, above n 57 (appearing as rules 4 and 8).

${ }^{80}$ See generally Bill of Rights, above $n 57$.

${ }^{81}$ See Telephone interview with Marcus Sanders (8 March 2004).
} 
A break is likely to be more competitive if only the first version of the 'snaking' norm is active.

Under the first definition, a 'snake' occurs if: (1) surfers A and B are both paddling for a wave; (2) A is further inside and has priority; and (3) B paddles across and directly in front of A preventing A from being able to catch the wave (but still enabling $B$ to catch the wave). ${ }^{82}$ Under this definition, a snake occurs when B deliberately gets in A's way. Snaking is also defined as follows:

Surfer A, in position and having waited his or her turn, begins to paddle for the wave. Surfer B (the snake) waits until A's focus is purely on catching the wave, then makes a quick move to the inside and takes off, claiming the wave. If both surfers end up riding, it appears $\mathrm{A}$ has dropped in and is in the wrong .... 83

Under this definition, B does not have to get in A's way to snake. Rather, B violates a sharing norm by racing inside $A$ to take advantage of the drop-in rule. This version of the snake norm is harder to enforce because it is difficult to determine if someone raced inside or simply had priority.

The two definitions of snaking are not mutually exclusive. Thus, snaking could be thought to cover both categories of behaviour. Nevertheless, each codification of surfing norms I have seen includes only one or the other definition. Under either definition, snaking rarely occurs by accident. ${ }^{84}$ This means that snaking is highly likely to antagonise its victim. Also, snaking requires skill so it is more likely to be practiced by talented and aggressive surfers. Thus, the presence of snaking behaviour is a good indicator that a particular surfing location is a highly competitive environment.

The preceding discussion shows that some lineups are more competitive and aggressive than others. Thus, surfers should pick breaks that suit their 'attitude'. ${ }^{85} \mathrm{~A}$ surfer can create resentment by entering a laidback lineup and proceeding to aggressively compete for waves. ${ }^{86}$ Also, a laidback surfer accustomed to sharing is likely to be frustrated and unhappy surfing in a competitive lineup.

It is also worth noting that some violations of sharing norms are treated more seriously. Resentment and conflict are especially likely if the surfer 'hogging' the waves is using an advantage other than skill. Longboards have more flotation and paddle speed than shortboards. Thus, longboarders can catch waves earlier from

\footnotetext{
${ }^{82}$ See Surfers Code of Ethics, above n 44, Young, above n 45, 8 (reproducing the 'Tribal Law of Surfing' plaque) (both providing diagrams of this form of 'snaking').

${ }^{83}$ Bill of Rights, above n 57.

${ }^{84}$ See ibid.

${ }^{85}$ See ibid (appearing as rule 1).

${ }^{86}$ Surfline calls the less competitive breaks 'Cool Zones' and suggests that if you are a competitive surfer then 'paddling out at a Cool Zone is likely to leave you feeling unsatisfied and your fellow surfers irritated by your competitive attitude.' Ibid.
} 
further back in the lineup and they have an advantage in the competition for waves. Thus, ' $[\mathrm{t}]$ he longboard rider should be absolutely clear that his or her craft provides an unfair paddling advantage which, if abused, will quickly lead to hostility from surfers who choose to ride shorter, more high performance equipment. ${ }^{87}$

The situation is more complicated when a surfer's advantages are based on skill. Highly skilled surfers generally enjoy higher status within the lineup. ${ }^{88}$ Thus, other surfers are less likely to sanction a skilled surfer's gluttony. At the very least, other surfers may have to accept that 'the best surfer's skills may earn him or her an occasional extra wave, or a wider opportunity to choose the precise wave he or she wants. ${ }^{89}$

\section{Abstract norms}

Some surfing norms are so abstract that they don't suggest specific conduct at all. These norms focus on the concept of 'respect'. For example, the slogan 'Give Respect to Get Respect' appears prominently on many codifications of surfing norms. The slogan appears in large text at the bottom of the plaque in Margaret River, Western Australia ${ }^{90}$ and it appears on a poster distributed in Eastern Australia. ${ }^{91}$ The slogan also appears in large text above the specific rules of ethics outlined on a website maintained by surfers from the New England region of the United States. ${ }^{92}$ Clearly, this slogan captures an idea important to surfers.

The concept of 'respect' also appears in other norms. These norms include:

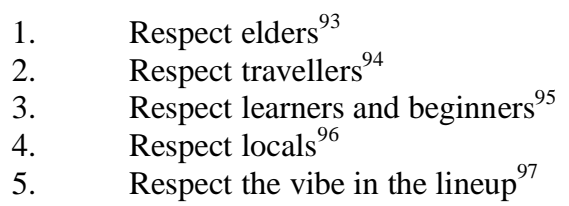

These 'respect' norms don't give clear guidance about behaviour. Thus, it may be difficult to detect and sanction violators. In fact, since I have defined a norm as something that gives third parties authority to sanction violators, a highly abstract rule is not a norm at all if detecting violators is impossible.

\footnotetext{
${ }^{87}$ Ibid (discussing rule 8 'Don't use your surfing advantages to abuse your fellow surfers').

${ }^{88}$ See Part V(E); Pearson, Surfing Subcultures, above n 5, 153.

${ }^{89}$ Bill of Rights, above n 57.

${ }^{90}$ See Young, above $\mathrm{n} 45$ (reproducing the 'Tribal Law of Surfing' plaque).

${ }^{91}$ See Surf Forum 1, above n 43, 242 (showing a reproduction of a poster created by the Surfrider Foundation of Australia).

${ }^{92}$ See, for example, Surfers Code of Ethics, above n 44.

${ }^{93}$ See Surf Forum 2, above n 1, 334 (commentary by Stephen Kuhn) (appearing as rule 10 on Kuhn's list).

${ }^{94}$ See ibid (appearing as rule 17).

${ }^{95}$ See ibid (appearing as rule 15).

${ }^{96}$ See ibid (appearing as rule 9); Bill of Rights, above n 57 (appearing as rule 5).

${ }^{97}$ See Bill of Rights, above $\mathrm{n} 57$ (appearing as rule 7).
} 
Perhaps the best way to think of surfers' 'respect' norms is to see them as 'abstract norms' in the sense used by McAdams. ${ }^{98}$ McAdams points out that we use the term 'norm' for both specific behavioural norms and for general expressions of sentiment such as 'be a loyal friend'. 99 McAdams suggests that the more specific norms can implement or provide meaning to the more abstract norms. ${ }^{100}$ For example, the specific norm 'pick up after your dog' may be a component of the abstract norm 'be a good neighbour'. In this way, specific norms provide the content to the abstract norms they instantiate. Moreover, violators of abstract norms can be punished whenever they violate a behavioural norm that instantiates the abstract norm. An abstract norm may provide the moral force behind a specific behavioural norm. ${ }^{101}$

In the surfing context, the obligation to 'respect' other surfers (such as locals and elders) may be nothing more that the obligation to observe all the concrete norms outlined above. Under this theory, the surfers' concept of 'respect' provides a moral foundation for their other norms. Essentially, the prominence of 'respect' talk suggests that surfers believe that their norms are more than just rules of convenience (like driving on the left or shaking hands with the right hand) but behaviours that demonstrate esteem for their fellow surfers.

Some surfers resist the idea that surf norms should be given this broader moral significance. For example, Australian journalist Fred Pawle says 'I don't go surfing to show respect to anyone. . . . I go out to enjoy myself, and am prepared to do it while causing my fellow surfers the least amount of grief. ${ }^{, 102}$ Under this view, surf norms should be seen as simple rules of the road which allow surfers to coexist with a minimum of inconvenience.

Pawle may also be resisting the 'respect' norm because he feels that some surfers misuse it in an attempt to get a larger share of waves. Pawle says 'respect is one of the most overused words in the English language. . . . [i]t usually means one person or group imposing a dubious set of standards on someone else, usually at their expense. ${ }^{, 103}$ For example, 'respecting locals' may involve more than just ensuring that you honour the drop-in norm around locals, it may involve allowing the locals to catch any waves they want. ${ }^{104}$ This would give the 'respect' norm a meaning independent of the concrete norms outlined above. Further discussion of this less cooperative version of the respect norm would take us into the crazy world of surfer localism which is reserved for Part V of this article.

\footnotetext{
${ }^{98}$ See McAdams, above n 34, 382-387.

99 Ibid 383.

${ }^{100}$ Ibid 386-87.

${ }^{101}$ Ibid 386.

${ }^{102}$ Pawle, above n 39, 99.

${ }^{103}$ Ibid 98-99.

${ }^{104}$ See Part V.
} 


\section{Sanctions}

Ellickson noted that the ranchers of Shasta County enforced their social norms through low cost sanctions such as negative gossip. ${ }^{105}$ In this context talk is cheap." ${ }^{\prime 106}$ Surfers may not have this low-cost option, however, because they frequently have to deal with strangers. Thus, the wronged surfer often has to engage in immediate and face to face sanctioning behaviour with an unfamiliar person.

Consider the following episode of sanctioning behaviour provided by author Daniel Duane. Duane wrote about returning to surfing after a long absence. He admits that '[i]m my time away from the water I'd forgotten the code, the traffic rules.'107 Unsurprisingly then, he soon violates the drop-in rule and ruins a wave ridden by a 'little Blond Apollo' who proceeds to scream insults at him. ${ }^{108}$ Duane notes 'his fury struck me as almost comical: aside from the fact that I had about fifty pounds on him, how could he know, in this day and age, that I didn't have a Glock in my car.' ${ }^{109}$ Duane notes that there is a 'confidence in humanity required to shout at a complete stranger.' ${ }^{110}$ As this confidence may be misplaced, sanctioning behaviour in the surf is a risky business.

At this point it is worth returning to the story of Nat Young's assault. This narrative helps illustrate the operation of a variety of surf norms and shows the risks involved with sanctioning behaviour. The assault took place at Angourie Point in New South Wales, Australia. Nat Young and longboard rider Michael Hutchison were both regular surfers at the point. There was lingering resentment between the surfers because Young believed that Hutchinson illegitimately used his advantages as a longboarder and 'took off on every set wave, something that isn't done in according to the rules of surfing.' 111 As noted above, a violation of the share-the-waves norm is most likely to be resented when it is perceived to be based on an unfair surfing advantage such as board length.

The incident itself began when Young took off on a wave despite the fact that another surfer had been on the inside. This would usually violate the drop-in rule but Young claims that the other surfer called him onto the wave, thus giving him permission to ride. Nevertheless, Hutchinson's son Luke believed that Young had dropped in on this surfer and began abusing Young for violating the drop-in rule (despite the fact that Young hadn't wronged Luke or Luke's father directly). Young claims that Luke was 'screaming obscenities at the top of his lungs.' 112 In

\footnotetext{
${ }^{105}$ See Ellickson, above n 27, 214.

106 Ibid.

${ }^{107}$ Daniel Duane, Caught Inside: A Surfer's Year on The California Coast (1996) 14.

${ }^{108}$ Ibid.

${ }^{109}$ Ibid.

${ }^{110}$ Ibid.

${ }^{111}$ Nat Young, 'Introduction', in Nat Young (ed), Surf Rage (2000) 45, 18 (note that Nat Young's perspective is the only public account of the assault) 112 Ibid.
} 
response, Young 'swatted him in the mouth' to get him to shut up. ${ }^{113}$ Shortly after this, Luke's father confronted Young on the beach and beat Young very severely.

Thus, it appears that the assault had two origins. First, there was the background of resentment between the parties based on an alleged violation of the share-the-waves norm. Second, there was a fuse provided by the son's allegedly unjustified sanctioning behaviour and Young's assault on the son in response. Thankfully, such assaults are not common. Nevertheless, the possibility of such assaults ensures that, from an individual perspective, surfing norms are costly to maintain. Thus, surfing norms provide a good example of the willingness of individuals to enforce norms through sanctions despite high costs.

\section{A comedy of the commons?}

Many researchers have lauded social norms as welfare maximising and highly efficient. ${ }^{114}$ On this view, "norms solve collective action problems by encouraging people to do useful things that they would not do without the relevant norms.' ${ }^{115}$ In fact, norms can solve difficult collective action and coordination problems very cheaply because they apply an informal and decentralised form of social control rather than an expensive centralised mechanism such as formal law. The optimistic view of norms has been supported by a variety of case studies. ${ }^{116}$

Although the optimistic view of social norms is prevalent, some writers are sceptical about the value of social norms. ${ }^{117}$ Accordingly, there are case studies providing examples of bad norms. For example, John Elster convincingly argues that feuding norms are neither individually rational nor welfare maximising. ${ }^{118}$ This is hardly a surprise. It seems obvious that a norm responsible for regular violent conflict on the basis of no more than perceived slights against honour is not welfare maximising. Nevertheless, some commentators argue that feuding norms are socially beneficial. ${ }^{119}$ The sheer implausibility of some of the arguments in favour of feuding norms ${ }^{120}$ suggests that some researchers seem compelled to argue that social norms are welfare maximising. Perhaps the idea that norms are socially beneficial has itself become a social norm among academics? This is too harsh, however, as even some of the most bullish supporters of norms accept that not all norms are beneficial or efficient. ${ }^{121}$

\footnotetext{
${ }^{113}$ Ibid.

${ }^{114}$ See, for example, Ellickson, above n 27, 167-83.

${ }_{115}$ Cass R Sunstein, 'Social Norms and Social Roles' (1996) 96 Columbia Law Review 903, 918.

${ }^{116}$ See, for example, West, above n 27; Ellickson, above n 27.

${ }^{117}$ See, for example, Eric A Posner, 'Law, Economics, and Inefficient Norms' (1996) 144 University of Pennsylvania Law Review 1697.

${ }^{118}$ See Jon Elster, 'Norms of Revenge' (1990) 100 Ethics 862, 872-883.

${ }^{119}$ See ibid 876-881.

${ }^{120}$ For example, Elster encounters the view that feuding norms among Montenegrins were beneficial because of the disunity caused by these norms. Apparently, this disunity actually protected the Montenegrins because it made them less of a threat to the Turkish Empire. See ibid 878.

${ }^{121}$ See, for example, Ellickson, above n 27, 169.
} 
Overall, surfing norms strongly support the optimistic view of social norms. These norms promote efficiency. I have already discussed the efficiency promoting properties of a one-surfer-per-wave norm. ${ }^{122}$ This norm is so fundamental to surfers that it is rarely even explicitly mentioned. The norm is simply implicit in the drop-in rule. The drop-in rule gives priority to the surfer who is best placed to have the longest and most enjoyable ride. This is because the person furthest to the inside on a wave is going to be able to ride it the longest. Moreover, being 'inside' places the surfer closest to the breaking part of the wave which is also the steepest and most thrilling part of the wave to ride. Thus, the drop-in rule is the most efficient way to implement the norm of one surfer per wave.

Other norms have similar efficiency promoting features. The paddle wide norm prevents waves from being wasted by paddling surfers getting in the way of riding surfers. The rule against pre-emptive paddling also prevents paddling surfers from wasting waves. ${ }^{123}$ The norm favouring communication is also clearly directed at preventing waste. Surfers have a responsibility to indicate which direction they intend to surf and whether they are actually going to catch waves. This prevents waves being wasted simply because other surfers were unsure about their intentions.

Finally, the norm requiring surfers to take off whenever they are 'called on' to a wave shows a similar distain for wasting waves. Nevertheless, although this norm reduces waste, it may not be welfare maximising. Surfers may be required to honour this norm even if they risk injury by taking off on a large set wave. ${ }^{124}$ Thus, the norm may not really benefit surfers. Surfers sometimes appear to take their opposition to waste to excessive lengths. Nevertheless, I believe that, overall, surfing norms provide very strong support for the optimistic view of norms.

Surfing norms only seem partly influenced by concerns about distribution. Equity plays a part in the 'share the waves' and 'don't abuse your surfing advantages' norms. Ellickson suggested that social norms governing workaday affairs are unlikely to be influenced by distributive considerations. ${ }^{125}$ It seems that surfing norms conflict with this suggestion. This is not a serious conflict, however. First, surfers do not import any external distributive concerns (i.e. you do not get more waves because you are poor). Moreover, the distributive norms are trumped by other norms such as the drop-in rule that comprise the central rules of the road for surfers. This shows that the efficiency norms are dominant. Moreover, distributive norms have most force when the violator is perceived to be abusing an unfair advantage such as extra board length. When a violator is getting extra waves because of skill he or she may not face any sanctions at all. ${ }^{126}$

\footnotetext{
${ }^{122}$ See Part II(B).

${ }^{123}$ See above $\mathrm{n} 54-55$ and accompanying text.

${ }^{124}$ See above $\mathrm{n} 74$ and accompanying text.

${ }^{125}$ See Ellickson, above n 27, 177.

${ }^{126}$ See above $\mathrm{n} 88-89$ and accompanying text.
} 
Overall, the focus of surf norms is on efficiency. Moreover, the norms work. Surf norms allow for millions of people around the world to regulate their activity with almost no state intervention. Violence in the surf is relatively rare despite the fact that surfers value waves very highly.

Ellickson suggests that efficient norms are most likely to emerge among close-knit groups. ${ }^{127}$ Other writers follow Ellickson in placing specific emphasis on the welfare maximising properties of norms developed by close-knit groups. ${ }^{128}$ Surfers, however, have developed a set of efficient norms despite the fact that they are not a close-knit group. The global surfing community is far too vast to be considered close-knit. Nevertheless, surfers around the world have developed a core set of norms that applies, with only minor variations, across different parts of the world. I have looked at descriptions of surf norms from Eastern Australia, ${ }^{129}$ Western Australia, ${ }^{130}$ New England, ${ }^{131}$ South Africa, ${ }^{132}$ and California. ${ }^{133}$ These accounts from around the world differ only in minor details and can easily be seen as describing a set of cross-cultural norms. Thus, surfers show that cooperative and efficient norms can emerge from a large and heterogeneous community. In fact, the norms of very close-knit surfing communities tend to be less cooperative. ${ }^{134}$ Some commentators suggest that close-knit groups may develop norms that externalise costs onto outsiders. ${ }^{135}$ The localism norms discussed in Part V fit this pattern.

The cooperative surfing norms provide support for a thesis advanced by Carol Rose. Rose has suggested that a tragedy of the commons is not inevitable in all circumstances and, furthermore, that some kinds of property are inherently public. ${ }^{136}$ Rose suggests some tragedies of the commons have been averted through successful informal management. ${ }^{137}$ She provides the examples of public pathways and navigable waterways. ${ }^{138}$ Courts have even recognised the success of informal management by recognising public property rights over such inherently public property. ${ }^{139}$ Rose argues that '[f]rom a resource management perspective, a group capable of generating its own customs ought to be a less objectionable holder of 'public prop-

\footnotetext{
${ }^{127}$ See, for example, Ellickson, above n 27, 169.

${ }^{128}$ See, for example, West, above n 27, 168 ('This article's central claim is that members of the Sumo firm, like members of other close-knit groups, have created . . . an organisational structure that maximized group welfare.') (emphasis added).

${ }^{129}$ See Surf Forum 2, above n 1, 333-34 (commentary by Stephen Kuhn); Surf Forum 1, above n 43, 242

(showing a reproduction of a poster created by the Surfrider Foundation of Australia).

${ }^{130}$ See Young, above $n$ 45, 8 (reproducing the 'Tribal Law of Surfing' plaque).

${ }^{131}$ See Surfers Code of Ethics, above n 44.

${ }^{132}$ See Jury, above n 47, 116.

${ }^{133}$ See Bill of Rights, above $\mathrm{n} 57$.

${ }^{134}$ See Part V.

${ }^{135}$ See, for example, Robert D Cooter, 'Decentralised Law for a Complex Economy: The Structural Approach to Adjudicating the New Law Merchant' (1996) 144 University of Pennsylvania Law Review 1643, 1684-85; Ellickson, above n 27, 169 (providing examples such as norms of racial intolerance).

${ }^{136}$ See Rose, above n 12.

${ }^{137}$ See ibid.

${ }^{138}$ Ibid 723-30

${ }^{139}$ Ibid.
} 
erty' than the unorganised general public, because a customary public comes closer to the management capacities of a government. ${ }^{, 40}$

Surfing may fit within this picture. Surfers are such a large group it seems unlikely that they would manage a resource any better than the general public. Nevertheless, surfers have shown themselves capable of generating their own customs regarding the management of their common resource. These customs are complex and subtle and would be extraordinarily difficult to implement through a formal governmental body. While under the management of these customs, the waves could be considered an inherently public property.

Interestingly, the surfers' commons shares an important feature with the other examples of inherently public property provided by Rose such as public paths and waterways. In these commons, overuse does not have the long-term adverse consequences that it can cause in other contexts. Thus, while over-fishing today can destroy future seasons, a failure to observe the drop-in rule today will not ruin tomorrow's waves. Similarly, overcrowding and uncooperative behaviour on a waterway is unlikely to prevent the waterway from being used as a thoroughfare tomorrow. This lowers the stakes involved in competition for the resource. For example, individuals don't have to worry about this being the last chance for them to use the resource before they fall victim to others' defection. Perhaps this is an essential feature of inherently public property.

Unfortunately, it is premature to declare a 'comedy of the commons.' In a true comedy of the commons there is an additional factor: greater use is actually a positive good. ${ }^{141}$ Surfing is not like this. Even though congestion does not deplete the resource, surfers do not actually want more congestion. Thus, the cooperative norms of surfing are not the end of the story. Surfing norms also include the uncooperative norms of localism and their attendant violence. Nevertheless, I think it makes sense to laud the success of cooperative surf norms before discussing localism. Although it will be seen that localism is a significant problem, I believe that dramatic stories about localism could distract from the fact that cooperative surf norms are an enormous success. ${ }^{142}$ Essentially, I don't want the reader to fall victim to availability bias and only remember crazy stories about the violent 'Bay Boys' of Palos Verdes. ${ }^{143}$ The reader should also remember that millions of people surf regularly around the world and violent conflict among these surfers remains rare.

\footnotetext{
${ }^{140}$ Ibid 743.

${ }^{141}$ See ibid 767-68 (noting that increased participation can enhance the value of many social and commercial activities).

${ }^{142}$ Justice Greg James makes the same point. See Surf Forum 1, above n 43, 233 (commentary by Justice Greg James) (arguing that press coverage of surfing violence, like recent sensationalist press coverage of home invasions, could make such incidents seem more frequent than they really are and lead to unnecessary regulation).

${ }^{143}$ Basically, availability bias is our tendency to believe that dramatic and memorable events are more common than they really are. For a good discussion of availability bias, see Amos Tversky and Daniel Kahneman, 'Availability: A heuristic for judging frequency and probability' (1973) 5 Cognitive Psychology 207-302. For crazy stories about the Bay Boys see Part VI(C).
} 


\section{Localism Norms (Preventing a Tragedy of the COMMONS?)}

Many surfers who've spent years of their lives learning the curves and moods of a powerful and alluring surf spot feel a sense of ownership that makes land-based property rights seem feeble in comparison. ${ }^{144}$

The cooperative norms of surfing are not the end of the story. A visiting surfer arriving at a new break will want to know the intensity of the 'localism' at the break. ${ }^{145}$ Localism can range from norms conferring some higher status on locals to norms that enforce extra-legal proprietary claims. At their most extreme, localism norms are enforced through violence.

Status has little role in the cooperative norms of surfing. Although beginners are obliged to surf at mellow breaks ${ }^{146}$ and longboarders must not abuse their advantages $^{147}$, the norms of surfing usually apply equally to all surfers. For example, the drop-in rule gives priority to the surfer on the inside even if that surfer is a beginner and the surfer on the outside is a former world champion. ${ }^{148}$ Localism injects status into the mix.

Essentially, localism is a diverse and variable set of norms conferring higher status and priority on a group of 'local' surfers. A surfer gains the status of being a 'local' through surfing a break regularly. ${ }^{149}$ Thus, a 'local' need not actually live near the break. However, a local does need to surf the break frequently enough that the other regular surfers recognise him or her as a regular. Localism relies on the 'locals' being able to distinguish locals from outsiders. Thus, it is possible for a surfer to claim priority as a local over someone who actually lives much closer to the break. ${ }^{150}$ The most important requirement to attain local status is to have a long history surfing at the break. Establishing this history is often referred to as 'paying dues'. ${ }^{151}$

The norms of localism are not as fixed as the basic cooperative norms of surfing. The most important differences are in the level of deference expected from visitors

\footnotetext{
${ }^{144}$ Nick Carroll, 'Defending the Faith', in Nat Young (ed) Surf Rage (2000) 54, 60.

145 As Dean Kronman told me, 'the main variation you have to worry about is the variation in the intensity of the localism.' Anthony Kronman, Personal communication February 2004.

${ }^{146}$ See above $n$ 76-77 and accompanying text.

${ }^{147}$ See above $\mathrm{n} 87$ and accompanying text.

${ }^{148}$ Recall that former world champion Nat Young was yelled at for allegedly violating the drop-in rule. See above n 112-13 and accompanying text.

${ }^{149}$ See Part V(E).

${ }^{150}$ See, for example, Bill of Rights, above n 57 ('The term 'local' has nothing to do with where a surfer's home is located, yet everything to do with his or her long-term history at a particular surf location.') (discussing rule 7 'When travelling, respect the local surfers').

${ }^{151}$ See, for example, Derek Rielly, 'Mainlining', in Nat Young (ed) Surf Rage (2000) 33, 39 (describing the 'lengthy dues paying exercise' expected from him by the locals when he moved to a new break).
} 
and the level of hostility demonstrated toward visitors. Localism can be considered mild, moderate or heavy depending on these differences. ${ }^{152}$

Milder forms of localism involve nothing more than an expectation that locals should receive a measure of additional deference. Surfing at a mildly localised break may involve no more than taking extra care not to drop in on locals and competing less aggressively for the best set waves. This mild form of localism serves as an extra layer of norms that is added to the cooperative norms of surfing. In contrast, surfing at a heavily localised break can mean risking serious assault. Consider the following description of the atmosphere at Lunada Bay in Los Angeles:

Notoriously localised by a crew that all know each other. Keep a low profile, walk softly and carry a big stick. Park your car blocks away, or have someone stay with the car. If it's not too crowded there is the remote possibility that you'll catch a couple of waves, and not be verbally or physically assaulted! ${ }^{153}$

In contrast to milder forms of localism, heavy localism displaces the cooperative norms of surfing as it aims for the outright exclusion on non-locals. The locals themselves may distribute waves according to ordinary surfing norms; they just refuse to apply the norms to outsiders.

Although I have divided localism into three categories, it is important note that these groupings are very flexible. It will be seen that the severity of localism varies along many dimensions. These include the level of deference expected from visitors, whether visitors encounter verbal abuse, whether locals tolerate disfavoured groups such as wave-ski riders and the frequency of violence and property damage. Nevertheless, the variation among these factors can be considered together as determining an overall level of hostility encountered by outsiders.

It is also worth noting that the local 'vibe' can change rapidly even at a single break. For example, a break may have an easygoing ambience for the first hours after dawn and then become very competitive a few hours later. ${ }^{154}$ A surfer who has already paid his 'dues' with the early morning locals can arrive at 8 am and encounter hostility from a different crowd of regulars. ${ }^{155}$

\footnotetext{
${ }^{152}$ I borrow these terms from Surfline. In its online travel guide to American breaks, Surfline rates the breaks according to 'local vibe'. See Surfline, Surfline: Travel

<http://www.surfline.com/travel/surfmaps/us/us.cfm> at 28 April 2004

${ }^{153}$ Wannasurf, Lunada Bay

<http://www.wannasurf.com/spot/North_America/USA_California/LA_County/lunada_bay/index.html> at 9 December 92003 (Wannasurf is a large online guide to the world's surf breaks).

${ }^{154}$ See Oscar Liivak, Personal communication. Oscar was a regular surfer at Santa Cruz's famous Steamer Lane.

${ }^{155}$ See ibid. Oscar claimed that the very early morning crowd at Steamer Lane consisted mostly of older surfers while the midmorning crowd consisted of younger surfers eager to establish their dominance.
} 


\section{A Mild localism}

As noted above, this form of localism is mostly compatible with the healthy norms of surfing. Essentially, 'mild localism' means showing extra deference to local surfers. This deference is shown through taking extra caution not to drop in on a local and through observing a few extra norms.

The norms (for visitors) of mild localism include:

1) Don't arrive in a large group ${ }^{156}$

2) Ease into the lineup (don't compete aggressively too early) ${ }^{157}$

3) Let locals surf most of the best set waves ${ }^{158}$

4) Take extra caution to avoid violating any ordinary surf norms (i.e. don't get in a local's way!)

Together, these concrete norms can implement the abstract norm of 'respect the locals'. Observing these norms demonstrates deference to the locals and helps mitigate the effects of crowding for the locals.

Surf journalist DC Green describes arriving with a group of five at a localised break where four surfers were already surfing: 'One guy strolled over from a van, leaned in and muttered, 'Look I'm not a local. But you guys better not all paddle out at once.' [My companion] already knew this unwritten crowd control law, but he thanked the guy all the same. ${ }^{159}$ This norm against travelling in large groups seems mainly directed at minimising the impact of crowding on locals. If localism is understood as being, at least in part, a reaction to overcrowding, then we might postulate that more crowding will lead to more severe localism. ${ }^{160}$ Thus, if visitors wish to minimise the severity of the localism they experience then they should take care to minimise the extent to which they are seen as a cause of crowding. Surfline recommends the following rule of thumb: 'if there's [sic] a few guys out: avoid increasing the numbers in the water by more than $25 \%, 161$

The next three norms serve the dual purpose of minimising the impact of crowding and conferring higher status on locals. Overall, these norms allow locals to set the tone (or, as surfers say, the 'vibe') of the surf session. Surfline advises visitors to 'take a back seat and let the local surfers dictate the pace of your surf, until they're confident enough of your intentions to give you a couple of set waves.'162

Notice that this implies that the locals can control the distribution of the set waves. At heavily localised breaks this control may be enforced through outright threats

\footnotetext{
${ }^{156}$ See for example, Bill of Rights, above n 57 ('Don't travel in large numbers.') (discussing rule 7 'When travelling, respect the local surfers').

${ }^{157}$ See ibid.

158 See ibid.

${ }^{159}$ See Green, above n 75, 39 .

${ }^{160}$ I discuss the relationship between localism and the threat of crowding in Part $\mathrm{V}(\mathrm{G})(3)$.

${ }^{161}$ Bill of Rights, above n 57 (discussing rule 7 'When travelling, respect the local surfers').

162 Ibid.
} 
and violence. Violence is not necessary, however. At breaks with milder forms of localism the locals may be able to control the distribution of waves simply through their knowledge of the break. If visitor competes too aggressively, 'a local (or more than one) will almost certainly use his or her superior knowledge of the spot to confuse and frustrate you., 163

Locals can 'frustrate' visitors by assertively using their experience and familiarity with the break to exploit a feature of the drop-in rule. Recall that the drop-in rule gives priority to the surfer who is closest to the peak. Successfully catching a wave very close to the peak can be very challenging because that is where the wave is at its steepest. Thus, the drop-in rule 'under competitive conditions can lead to a cycle in which surfers may attempt to take-off in ever more 'tight' situations. ${ }^{, 164}$ This means that it will require considerable skill to get priority. ${ }^{165}$ In this situation a group of experienced locals can use their familiarity with the wave to dominate the break. ${ }^{166}$ Thus, visitors may have to effectively wait for 'permission' to get a prized set wave. Sometimes this permission will take the form of an explicit invitation to catch a wave. ${ }^{167}$ Other times visitors will simply wait for locals to relax and compete less aggressively before they will attempt to catch a prize wave.

\section{B Moderate localism}

Violence among surfers is a problem which has existed for many years. Typically, this involves 'localism,' in which persons who frequent a certain area will attempt to discourage others from using the area by means of escalating intimidation techniques. Most often, this is manifested by threats at varying levels or attempts to cut off the non-local surfer attempting to surf. When these are ineffective, the problem occasionally rises to physical violence. ${ }^{168}$

There is a fundamental difference between mild localism and what I am calling moderate and heavy localism. The latter forms of localism involve active efforts to discourage visitors from surfing a break while mild localism merely seeks deference and especially good behaviour from visitors. Thus, at moderately and heavily localised breaks the local surfers claim quasi-proprietary rights over the surf break. These rights are enforced through informal and often illegal tactics. The intensity of the tactics employed determines how 'localised' the break is.

\footnotetext{
${ }^{163}$ Ibid.

${ }^{164}$ Pearson, above n 5, 155.

165 'On some extremely competitive occasions, the take-offs are so critical that the wave is virtually unmakeable even for the very best surfers.' Ibid.

${ }^{166}$ For example, consider the following advice for visitors to a Western Australian surf break known as Jake's Corner. 'Locals have got the take off zone wired. Expect scraps.' Wannasurf, Jakes Point <http://www.wannasurf.com/spot/Australia_Pacific/Australia_WA/Kalbarri/jakes_point/index.html> at 8 February 2004. My personal experiences at Jake's Corner confirmed the accuracy of this observation.

${ }^{167}$ See above $\mathrm{n} 75$ and accompanying text.

${ }^{168}$ Memorandum from Chief Lifeguard B Christmas Brewster, to City of San Diego Legislation Sponsorship Program (1999) (supporting the proposed Open Waves Act) (on file with author).
} 
Moderate localism will tolerate some outsiders while heavy localism aims for the outright exclusion of visiting surfers. The tools of these forms of localism include 'stink-eye', explicit demands to leave, deliberately getting in the way of visiting surfers, marking territory through graffiti, property damage and physical violence. Although moderate localism can use all of these tools, physical violence and property damage will be rare and may be limited to certain out-groups such as bodyboarders or wave-ski riders.

The mildest form of intimidation or discouragement encountered by visiting surfers is the dirty look, or, as surfers call it, 'stink-eye'. ${ }^{169}$ Stink-eye is probably the easiest way to make visitors feel unwelcome without breaking the law or risking a violent response from a visitor. Of course, the downside to such a mild form of intimidation is that many visitors will simply ignore it. Thus, stink-eye alone is unlikely to succeed in keeping away crowds and locals may have to increase their intimidation.

'The most common tactics, and the most difficult to police, are threats and taunts. ${ }^{170}$ Threats and insults are the next level of intimidation after stink-eye. A typical verbal act of localism would involve a local surfer telling a visitor that the break is for 'locals only'. ${ }^{171}$ Along with verbal threats, surfers may also return to their cars to find a note under the windscreen wiper discouraging them from coming back. $^{172}$

Verbal intimidation can vary from a simple insult (such as calling a visiting surfer a 'kook') to an illegal threat. For example, a Brazilian surfer visiting Palos Verdes in Los Angeles reported being surrounded by 15 locals who told him that they would 'break my face' if he surfed there. ${ }^{173}$ Verbal intimidation, even when illegal, has the advantage of being almost impossible to prosecute. ${ }^{174}$ Moreover, this form of intimidation is almost never reported to authorities even when it is routine. ${ }^{175}$

Locals also use physical markers or signs to intimidate visitors. While the waves themselves cannot be marked, nearby buildings and parking lots are often explicitly marked by graffiti telling visitors to leave. Anti-visitor graffiti can sometimes be directed at a specific group of outsiders. For example, graffiti saying "LA go home' . . . used to be painted onto the flyover near Rincon Point beach, south of

\footnotetext{
${ }^{169}$ See, for example, Mike Kew, 'Californication', in Nat Young (ed) Surf Rage (2000) 100, 102; Glen Hening, 'Stain on the Soul', in Nat Young (ed) Surf Rage (2000) 131, 142.

170 'Californians defending surf turf: Some turn to violence to control best beaches', The Dallas Morning News, 27 September 1998.

${ }^{171}$ See Kew, above n 169, 108-09.

${ }^{172}$ See ibid 124-25.

${ }^{173}$ See ibid 112. This act of localism may violate CAL PENAL CODE $§ 422$ (2004) (prohibiting threats to commit a crime which could result in death or serious bodily injury).

${ }^{174}$ See Telephone interview with Chris Brewster (14 November 2003) (on file with author) (Chris Brewster was formerly chief lifeguard in San Diego).

${ }^{175}$ See ibid.
} 
Santa Barbara, one of the best surf sites on the California coast. ${ }^{, 176}$ More commonly, visitors will encounter graffiti with the basic message of localism: 'Locals only'. ${ }^{177}$ At a break I often visit (but never surf) in Rhode Island 'locals only' was, until recently, painted in large red letters in the middle of the parking lot.

Locals also make things unpleasant for visitors by deliberately dropping in on them. Deliberately dropping in on a surfer is known as 'fading'. ${ }^{178}$ If the locals regularly fade a visitor then they can effectively ruin all of his or her waves. Usually, a victim of fading would have authority to sanction the person who has violated the drop-in rule. At a localised break, however, the locals may react very negatively to being sanctioned by outsiders. Surf journalist Derek Rielly claims that he has 'seen a Burleigh local drop in on a visiting surfer, veer threateningly toward him, collide, then surface throwing punches at the stunned bloke. ${ }^{, 179}$ Visitors will often quietly accept a fade because of fear of such behaviour. Thus, localism can fundamentally alter the most important cooperative norm of surfing.

Fading serves the dual purpose of mitigating the effects of crowding and demonstrating the superior status of locals. Fading allows locals to take more waves, particularly when they are otherwise struggling to compete. 'If a local gets frustrated, the next wave is his, whether he is on the inside or not. . . [ $t$ ]his is one of the variations on the drop-in rule, and one that is understood by all surfers. ${ }^{180}$ Fading can also reduce crowding by discouraging visitors from returning.

When visitors accept fading they acknowledge the superior status of locals. As one local explained:

Locals don't fade each other. But if that fella's [a visitor's] ability is good enough and he deals with it [being faded] without reacting verbally or physically, we'll stop doing it. If he deals with it, he gets respect quicker than a loudmouth who's got a good surfing ability. ${ }^{181}$

Thus, quietly accepting fading is a form of 'paying dues' that might allow a visitor to gain 'respect' from the locals.

Moderate localism can also involve attempts to completely exclude less favoured surfing groups such as bodyboarders and wave-ski riders. Bodyboarders (who are sometimes derisively called 'spongers' by other surfers) have an advantage over other surfers because they do not need to stand up when they catch a wave. This means that bodyboarders can catch steep waves close to the peak more easily than surfers with a similar level of experience. This gives bodyboarders an advantage

\footnotetext{
${ }^{176}$ See, for example, Campbell, above $\mathrm{n} 1$.

${ }^{177}$ See Jury, above n 47, 136 (displaying a photo of graffiti saying 'LOCALS ONLY' on a wall at Glen Beach in Durban, South Africa).

${ }^{178}$ See Pawle, above n 39, 95.

${ }^{179}$ Rielly, above n 151, 51 (Burleigh is a world class point break in Queensland Australia).

${ }^{180}$ Pawle, above n 39, 89.

${ }^{181}$ Ibid 95 (quoting Burleigh local Eric van Druten).
} 
under the drop-in rule and can breed resentment, especially in crowded conditions. Wave-ski riders also have an advantage over other surfers because of their much greater paddle speed. Thus, it is unsurprising that bodyboarders and wave-ski riders encounter the most hostility at localised breaks. When Stephen Kuhn asked surfers in eastern Australia to name rules of the surf, some responded that the rules of the surf simply did not apply to bodyboarders. ${ }^{182}$

Adam Koleits is a former semi-professional surfer and a local at Trigg Point in Perth, Australia. In an interview, Koleits described the Trigg locals' attempts to rid their break of bodyboarders and wave-ski riders. ${ }^{183}$ He claimed that ' $[\mathrm{t}]$ he Point is out of control still, but if we let those goat-boats [wave-skis] come through, plus the esky lids [bodyboarders], it would be twice as packed with not one bit of respect. ${ }^{, 184}$ Strategies for removing wave-skiers included stealing paddles and turning skis upside down to force the rider to eject from his safety belt. ${ }^{185}$

Koleits claims that ordinary surfers are not met with the same level of hostility. He says that he accepts ordinary surfers because 'we've all got to surf. . . . [b]ut the other types of craft at crowded spots, they're pushing their luck. ${ }^{, 86}$ Highly competent surfers in particular will be accepted. Koleits claimed that ' $[\mathrm{t}]$ he locals are friendly to anyone who can pull a bottom turn and do a belt. ${ }^{, 187}$

Finally, if a visitor makes the mistake of dropping in on a local he or she may be a victim of a 'spearing'. A spearing occurs when a surfer deliberately shoots his or her board at another surfer. ${ }^{188}$ A surfer is particularly vulnerable to this form of assault after dropping in. This is because the surfer will be directly in front of an annoyed surfer who is already riding the wave and thus has momentum to shoot out his or her board. ${ }^{189}$

\section{Heavy localism}

Heavy localism aims at the outright exclusion of non-locals. Heavy localism includes all of the intimidation tools of moderate localism but applies these tools with greater frequency and severity. Heavy localism often includes physical violence and property damage. Visitors to heavily localised breaks will often be immediately confronted with intimidation. If visitors are not deterred by this intimidation they risk assault.

\footnotetext{
${ }^{182}$ See Surf Forum 2, above n 1, 335 (commentary by Stephen Kuhn).

${ }^{183}$ See Pawle, above n 39, 90-93.

${ }^{184}$ Ibid 91.

185 See ibid.

186 Ibid.

${ }^{187}$ Ibid.

${ }^{188}$ See Alex Salkever, 'Surge in Surfers Leads to More Violence on the Waves', Christian Science Monitor, 24 February 1999, 2 ('Surfers often try to spear or run over other surfers with their boards.').

${ }^{189}$ In October of 2003, I saw an attempted spearing at the (normally peaceful) Town Beach in Narragansett, Rhode Island. Less than 20 feet away from me a surfer narrowly missed injury after a board was speared forcefully (and skilfully) in his direction. The victim had blatantly dropped in on the other surfer. The surfer who had attempted the spearing then continued to scream profanities at the surfer who had dropped in. The victim wisely paddled to another area of the beach.
} 
The locals at Lunada Bay in the Palos Verdes Estates neighbourhood of Los Angeles provide one of the most infamous examples of localism. ${ }^{190}$ The Lunada Bay locals are known as the 'Bay Boys'. In this subpart, I will focus on the Bay Boys as a discussion of their localism will cover all of the tactics of heavy localism.

The first thing to note is that the Bay Boys are very close-knit. 'The Bay Boys proudly describe themselves as a brotherhood - an endless fraternity from father to son - so close, so loyal that it dictates their social life and business dealings. ${ }^{, 191}$ Their home, Palos Verdes, is one of the most exclusive areas of Los Angeles. ${ }^{192}$ Despite the price of the real estate, the Lunada Bay surf break is below a public park and is supposed to be open to the public. ${ }^{193}$

The break at Lunada Bay is at the bottom of a very steep hill that is almost a cliff. Surfers need to park their cars at the top of this hill, as there is no road down. In fact, there is no maintained footpath down the hill so the descent is challenging for those who are unfamiliar with the landscape. ${ }^{194}$ The locals prefer this situation as it 'keeps the traffic down.' 195 This geography also makes the break easier for the locals to defend through intimidation. Visitors must arrive and park at the top of the hill and then descend on a particular path. Thus, a handful of locals can keep a vigil at the top of the cliff and confront any visitor. ${ }^{196}$

A small set of Bay Boys sometimes will keep a vigil at the top of the cliff while others surf. These locals will warn visiting non-surfers about the dangerous descent to the beach. ${ }^{197}$ They will also warn visiting surfers of the dangers of descending the cliffs. Of course, they make it clear to the surfers they will provide most of this danger themselves. As one Bay Boy put it, '[w]e promise [any visiting surfer] a very humiliating experience. ... [w] tell him 20 grown men will be in his face. ${ }^{198}$ Sadly, the visitor is well advised to follow this advice to leave as the Bay Boys' tactics will quickly escalate if he or she actually tries to surf there.

If he or she manages to pass any Bay Boys at the top of the cliff, the visitor then has to descend. This leaves the visitor vulnerable to rocks thrown from above. ${ }^{199}$ An

\footnotetext{
${ }^{190}$ See, for example, above n 153 and accompanying text. Surfline usually rates the 'local vibe' with words like 'none', 'moderate' or 'heavy'. For Lunada Bay, Surfline rates the local vibe as 'nuclear'! See Surfline, Surfline Travel: Lunada Bay,

<http://www.surfline.com/travel/surfmaps/us/la_county/lunada_bay.cfm> at 7 February 2004.

${ }^{191}$ Michael Goodman, 'Coastal Nostra: Surf Gangs in Los Angeles, CA', Los Angeles Magazine, June 1996, 72 .

${ }^{192}$ See Surfline, Fringe Benefits

<http://www.surfline.com/travel/surfmaps/us/la_county/haggertys_ely.cfm> at 2 February 2004 (Surfline interview with Palos Verdes surfer Tracy Ely) (heinafter Fringe Benefits).

${ }^{193}$ See Kew, above n 169, 114.

${ }^{194}$ See Goodman, above n 191.

195 Ibid (quoting a Bay Boy).

${ }^{196}$ This situation can be contrasted to a typical beach break which will have many avenues of approach.

${ }^{197}$ See Goodman, above n 191.

${ }^{198}$ Ibid (quoting a young member of the Bay Boys).

199 See ibid.
} 
alternative option would be to arrive by boat. Unfortunately, as Randy Meistrel found out, boaters still have to deal with the Bay Boys who are already in the water:

Randy Meistrel tried to avoid cliff fights and slashed tires by anchoring . . . outside Lunada Bay, then paddling in to surf. Bay Boys swarmed him. 'Somebody grabbed me. I took a swing. Four guys were holding me under and punching me.' He says he broke free and paddled back to his boat. $^{200}$

Unsurprisingly, this violent attack was successful in deterring future boating attempts from Meistrel. ${ }^{201}$

Surfers who arrive by car risk vandalism to their vehicle. It is very hard to monitor one's vehicle while in the water surfing. Thus, damaging cars is a common intimidation tactic at heavily localised breaks. ${ }^{202}$ At a heavily localised break in South Australia visitors have had windscreens smashed and have even had cars pushed off cliffs. $^{203}$ At Lunada Bay, vandalism is so common that visiting surfers have been advised to bring somebody to watch their car. ${ }^{204}$

The Bay Boys have been quite creative with their violence and do not limit themselves to throwing stones and punches. Some visitors report receiving cuts on their feet after Bay Boys left glass on the path while they were surfing. ${ }^{205}$ Another nonlocal, after bravely persisting with surfing at Lunada Bay finally 'saw the light' after some Bay Boys shot at him with a pellet gun. ${ }^{206}$ Obviously, violent tactics like these could place the Bay Boys at risk of arrest. I shall discuss why the Bay Boys have largely been able to avoid police attention in Part VI(B) below.

The severe tactics of heavy localism, such as those practiced by the Bay Boys, can attract publicity. ${ }^{207}$ For example, Tracks magazine recently published a list of the worst breaks in Australia for an outsider to visit. ${ }^{208}$ Generally, locals try to discourage publicity for their break. ${ }^{209}$ If the publicity is sufficiently negative, however, it can help to discourage visitors. One Bay Boy greeted a visiting journalist by telling him to 'keep writing that this is a war zone ... scare 'em away. . . . [w]e don't like riffraff comin' up here showing their fat butts in front of these million-dollar 
homes. ${ }^{210}$ Thus, as long as the break is infamous as well as famous, publicity may deter visitors from showing up at all.

The goals and techniques of localism, unsurprisingly, will often take on a local flavour. In Hawaii, the intimidation tactics of localism are usually directed most strongly at non-local surfers who are not native Hawaiians. ${ }^{211}$ In Puerto Escondido, Mexico, where the local surfers are usually much poorer than the visitors, some locals have demanded that visitors give them surfing equipment (even boards) to avoid local hassles. ${ }^{212}$ Nevertheless, the intimidation tactics of heavy localism are similar wherever it is practiced. The variation among localism is mostly in the frequency and severity with which the intimidation tactics are applied. The Bay Boys of Palos Verdes represent the extreme end of the localism continuum.

\section{Localism tied to land-based property rights}

As noted above, it is usually possible to become a 'local' at a break without owning property nearby. Even the Bay Boys include a few non-residents of Palos Verdes in their ranks. ${ }^{213}$ A very different form of localism has arisen at a small number of surf breaks, however. At these breaks, the localism is explicitly tied to ownership of nearby property. Normally, a surfer can seek acceptance by the locals through showing deference to them and surfing frequently enough to be seen as a regular. Surfers call this process 'paying dues'. In contrast, at a small number of breaks a surfer can 'pay dues' by actually paying dues. This might involve buying property or simply paying to stay at a surf resort. I will refer to this form of localism as 'cash localism'.

The most famous location of cash localism is the Hollister Ranch near Santa Barbara, known to surfers simply as The Ranch. The Ranch has something of a 'mythic history' for Californian surfers. ${ }^{214}$ The Hollister Ranch was subdivided in the early 1970 s. $^{215}$ The new property owners put the surfing community on notice that access to the surf breaks was to be limited to property owners. In July 1972, the manager of the Hollister Ranch, Dick Larue, announced to Surfer magazine that 'The Ranch is closed.' ${ }^{, 16}$ He said 'I know this article is going to come out in a magazine that's read by all the surfers in the world . . . and I just have to tell the

\footnotetext{
${ }^{210}$ Goodman, above $\mathrm{n} 191$ (first ellipsis in original).

${ }^{211}$ See, for example, McHugh, above n 2 (discussing Bob Wise's experience in Hawaii where, as the only white at a break, he was told to leave).

${ }^{212}$ See Surfer, The SURFER Interview: Coco Nogales (2003)

<http://surfermag.com/currentissue/cocoint/index1.html> at 24 October 2003 (no longer available online, on file with author) The interviewer says that Mr. Nogales '[u]sed to be one of the most notorious enforcers of Puerto Escondido's brutal localism.' Ibid.

${ }^{213}$ See Goodman, above n 191 ('Important for acceptance [into the Bay Boys], but neither essential nor automatic, is living - or at least having grown up - in Palos Verdes Estates. . . Privileges are sometimes extended to an aspirant living in one of the neighbouring peninsula communities.').

${ }^{214}$ Anthony Kronman, Personal communication February 2004

${ }^{215}$ See Kew, above n 169, 118.

${ }^{216}$ Ibid (excerpting the Surfer article).
} 
kids - the only way they can use The Ranch is to buy a parcel. ${ }^{217}$ Today, a surfer can gain recreation rights to The Ranch by purchasing a twelfth-interest in a parcel (costing approximately $\$ 125,000){ }^{218}$

The property owners of The Ranch only control the land-based access to the surf breaks. Thus, it is possible for surfers to travel to The Ranch's famous surf via boat. The result has been 'a venomous owner-versus-boater feud. ${ }^{219}$ The owners use the tactics of heavy localism to discourage boaters. ${ }^{20}$ In one famous incident, 'Angie Reno, one of surfing's great talents . . . had to fend off a machete attack., ${ }^{221}$ Even invited guests of owners can encounter hostility. Glen Hening reports that while at The Ranch with two friends, both of whom were 'parcel owners who have surfed The Ranch for decades, we couldn't surf Rights and Lefts. . . . seems that given who was out at R\&Ls that day, showing up with even one guest was verboten. $^{222}$

The difference between cash localism and ordinary surf localism can lead to distinct tensions. In the words of a regular boater:

That whole scene bugs me. I've spent a lot of time along that stretch of coast since my first trip in 1973. I've travelled in by car and by boat. Just because some punk comes up with the scratch for a twelfth-interest in a piece of dirt eight miles from the beach hardly gives him the right to tell me how I should pursue my boating interests. ${ }^{223}$

This boater resents being prevented from becoming accepted at The Ranch. Under the norms of traditional localism, a boater might be able to 'pay dues' at The Ranch and become accepted as a local (or at least tolerated by the locals). Under The Ranch's cash localism, however, someone with around $\$ 125,000$ can jump the queue and become an 'instant local'. It is not surprising that this annoys the boaters, some of whom have been surfing The Ranch for decades.

Another form of cash localism involves surf tourism. Land-based developers have claimed exclusive surfing rights at nearby breaks. For example, at Tuvarua in Fiji:

A group of Americans built a resort then claimed exclusive surfing rights to a reef just off the island and another a fifteen minute boat ride away. Money was paid to local tribes to enforce this self-created law and surfers

\footnotetext{
217 Ibid.

218 Anthony Kronman, Personal communication February 2004.

219 Kew, above n $169,118$.

${ }^{220}$ Dean Kronman has once surfed at The Ranch as a guest of an owner. He told me that his host claimed that boaters were only likely to encounter hostility if they arrived in large groups. Anthony Kronman, Personal communication February 2004.

${ }^{221}$ See Hening, above n 169, 140.

${ }^{222}$ Ibid. One of Glen's hosts said, 'I don't want my tires flattened again.' Ibid.

${ }^{223}$ Kew, above n 169, 121.
} 
from resorts on other islands daring to ride the reefs were told to leave or, worse, became victims of violence. ${ }^{224}$

The owner of a resort in the Maldives also claims exclusive rights to a surf break. ${ }^{225}$ The cash localism of Tuvarua is very different from traditional localism. First, like at The Ranch, a surfer can become a 'local' by paying money. In Tuvarua surfers become 'temporary locals' by paying to stay at the correct resort. Tuvarua is different from The Ranch, however. At The Ranch it is the locals themselves that must defend 'their' turf from the boaters. In Tuvarua the task of intimidation has been subcontracted to paid enforcers. Thus, in Tuvarua we have something that, even though it is not sanctioned by the state, looks a lot like fee simple.

\section{E Other norms among locals}

In this subpart, I shall complete my description of localism by reviewing some of the norms that govern the behaviour of locals. Norms govern the process of becoming a local and also govern the responsibilities of locals to each other. For example, locals may have a duty to prevent publicity of their break. Also, locals often have strong internal hierarchies that influence the obligations of individual members.

I have already partly discussed some of the norms governing the process of becoming a local. Essentially, the process involves slowly gaining acceptance by regularly surfing a break while showing deference to the established locals. ${ }^{226}$ A new arrival can try to gain acceptance and establish familiarity by starting out at less desirable nearby breaks. Oscar Liivak told me about his experience establishing himself at Santa Cruz's famous Steamer Lane. ${ }^{227}$ After moving to the area, Oscar began surfing regularly at the least desirable of Steamer Lane's three peaks. After Oscar had spent 5 months surfing almost every day at this spot, an established local paddled up to Oscar and told him he could move up to the most desirable peak. The duration of a dues-paying process like this can vary widely. At many breaks it can take years to become accepted as a local. ${ }^{228}$

As might be expected, the heavier the localism the harder it is to be accepted. Once again, the Bay Boys provide an extreme case. Consider the experience of Tracy Ely. Mr. Ely has surfed in Palos Verdes for decades. ${ }^{229}$ Moreover, his wife went to high school with many of the Bay Boys and he has often socialised with them. He has 'surfed with them at other breaks, just not Lunada. ${ }^{230}$ Despite being familiar to the Bay Boys both socially and as a surfer, Ely has never been 'invited' to surf with them at Lunada and he knows that he's not 'welcome' to surf there. ${ }^{231}$ Ely says that

\footnotetext{
${ }^{224}$ Rielly, above n 151, 49.

225 See ibid.

226 See above n 147-51 and accompanying text.

227 See Oskar Liivak, Personal communication.

${ }_{22}$ See Rielly, above n 151, 40 (describing a dues-paying exercise at Burleigh that '[w]ent on for years').

${ }^{229}$ See Fringe Benefits, above n 192.

230 Ibid.

231 Ibid.
} 
'[i]t's a generational thing up there now: you've got guys surfing out there who are 40 , and now their kids are surfing out there. ${ }^{232}$ Thus, at Lunada Bay it seems that the only way to become a local is to be the child of a Bay Boy.

After being accepted by the locals, a surfer will usually start at the bottom of a hierarchy. Young surfers (often known as 'grommets') are expected to show deference to older locals. Trigg local Adam Koleits says that '[w]hen I was young you had to earn your respect. . . . [w] did cheeky things but we didn't push it.' ${ }^{233}$ If the young surfers 'stepped out of line in those days you expected to get a bit of payback. ${ }^{234}$ Koleits claims after he dropped in on an older surfer 'the guy got me and threw me head-first into a glass recycling bin. ${ }^{235}$ Koleits claims that the older surfers deserve a greater share of the waves because they 'have waited in line for a long time. ${ }^{236}$

In Lunada Bay the older surfers get to delegate the task of intimidating outsiders to the younger surfers. Journalist Michael Goodman interviewed '[a] Bay Boy with 28 years [sic] seniority - who agreed to talk only if granted anonymity. ${ }^{237}$ This Bay Boy told Goodman that while "constant vigilance against outsiders 'is up to all of us,' .. . the actual 'hassling' of intruders most often falls to the young. ${ }^{, 238}$ A surfer's ability will also influence his place in the hierarchy. The way to be 'socially upwardly mobile' at a surf break is to improve your surfing. ${ }^{239}$ Surfers generally find that 'the better you surfed, the higher you sat in the chain of authority and status. ${ }^{240}$ Dominant surfers can enjoy considerable privileges. For example, a 'local hero' can have 'priority just by paddling for a wave.' ${ }^{241}$ Consider the following story:

I remember a time when a Brazilian guy . . . took off behind Gerry Lopez at Pipeline. I though it was so rude of him - after all, Gerry is a household name in the Islands and the King of Pipe. Who would ever think of hassling him for waves? Suffice to say [the Brazilian] didn't last long at Pipe - or even catch any more waves that day. ${ }^{242}$

What is remarkable about this tale is that the author believes that it is rude to take off behind Gerry Lopez. Under the drop-in rule, the surfer behind Lopez would have priority. Nevertheless, Lopez's status is such that surfers violate a local norm simply by competing with him for waves at Pipeline.

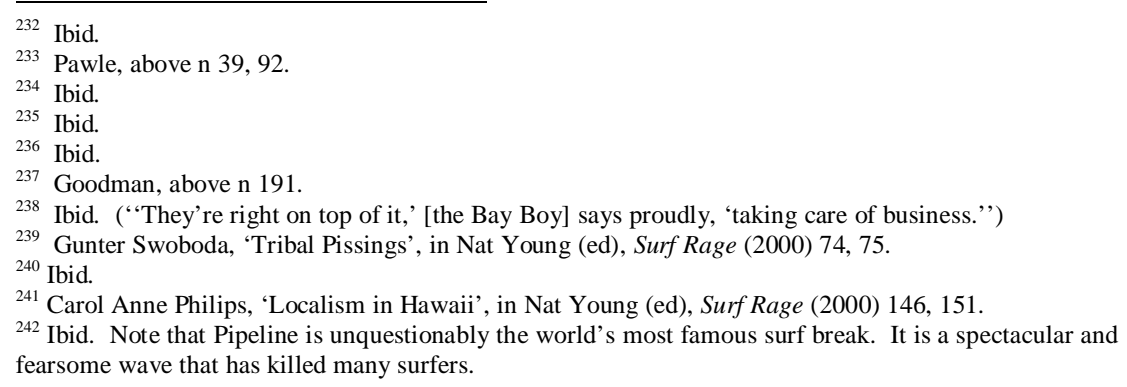


Another important norm of localism requires locals to minimise or prevent publicity of their break. Before the break became well known, locals at a break near Santa Cruz parked their cars well away from the surf so as not to draw attention to their spot. $^{243}$ The locals 'used to park a mile up the highway ... and walk down ... just to throw off the Valleys [non-local surfers]. ${ }^{244}$ Failure to observe this practice was punished. A local explained that ' $[\mathrm{w}]$ henever some geek parked too close ... we'd smash their headlights and leave a note on the windshield telling them where to park and how to walk down here. ${ }^{245}$

At heavily localised breaks even locals can be sanctioned for failing to prevent publicity for a break. Surf journalist DC Green suffered a harrowing ordeal at the hands of the locals at a break he deliberately misnames 'Saltbush'. ${ }^{246}$ A local told them to leave the area after Green's photographer set up his camera. The local explained that if the other locals saw that he had let them take photos then the other locals would throw rocks at him as well. ${ }^{247}$

The norm discouraging publicity can make the work of surf journalists quite difficult as they often encounter hostility from locals. ${ }^{248}$ A surf photographer at Lunada Bay 'reports that after he was threatened, he resorted to shooting from a station wagon with one-way windows. ${ }^{249}$ In response to this kind of pressure, surf journalists often deliberately misname the breaks they cover and many (if not most) of the photograph captions in surf magazines do not name the relevant break. ${ }^{250}$

\section{F The surf gangs of California?}

There is a striking parallel between surfer localism and the behaviour revealed in Acheson's famous studies of lobster fisherman. James M. Acheson has spent many years studying the behaviour of groups he has named the 'lobster gangs' of Maine. $^{251}$ These lobster gangs apply their own set of extra-legal localism norms to regulate the Maine lobster industry.

Acheson discovered that, in order to fish for lobster in Maine, one had to be a member of a "harbour gang. ${ }^{252}$ Each harbour gang has its own fishing territory. ${ }^{253}$

\footnotetext{
${ }^{243}$ See Duane, above n 107, 46.

244 Ibid.

245 Ibid.

246 See Green, above n 75. Anyone familiar with Australian surfing lore would easily guess that Green is writing about the infamous South Australian break called 'Cactus'.

${ }^{247}$ See ibid 184

248 See, for example, Carroll, above n 144, 64-71 (describing threats and violence perpetrated by locals against visiting surf journalists and photographers).

${ }^{249}$ Goodman, above n 191.

${ }^{250}$ See Carroll, above n 144, 64-71.

251 See generally James M Acheson, The Lobster Gangs of Maine (1988).

252 See James M Acheson, 'Variations in Traditional Inshore Fishing Rights in Maine Lobstering Communities', in Raoul Andersen (ed), North Atlantic Maritime Cultures (1970) 253, 253.

${ }^{253}$ See ibid 253-54.
} 
The harbour gangs are unofficial organisations and their territories are not recognised by the state. Thus, the harbour gangs themselves have to defend their fishing range. '[L]ocal norms regarding both entry into harbour gangs and the maintenance of boundaries are enforceable by the use of violence which is sanctioned locally. ${ }^{, 254}$

Aspiring lobster fishermen have to 'pay dues' in a similar manner to surfers wishing to gain acceptance at a localised break. In both cases, the aspirant should gradually ease his or her way into the community while scrupulously obeying the local norms. Acheson claims that ' $\mathrm{t}] \mathrm{h}$ he most important single factor influencing entry into a harbour gang is willingness to abide by the local norms regarding lobstering. ${ }^{255}$ Gradual entry is also important:

Anyone seeking to go lobstering will experience some degree of hostility from those already established in the business. Some men never are accepted. A local boy will have relatively little trouble if he is a long-time resident of the community, if his father's family is established in lobstering ... . His chances of success are greatly enhanced if he begins fishing from a skiff with a few traps while still in high school and then slowly expands to become a full-time lobsterman. ${ }^{256}$

This account could easily be adapted to describe surfer localism.

Like surfers, lobstermen defend their territory through escalating sanctions. Locals will usually provide a warning in response to the first intrusion. A warning can be provided by slightly molesting traps or by using an established signal (such as tying certain kinds of knots in the ropes attached to a trap). ${ }^{257}$ Similarly, surfers usually begin by warning intruders verbally, through graffiti or through notes placed under windshield wipers. The next step for lobstermen is deliberately leaving the visitor's traps open. ${ }^{258}$ This takes away the visitor's benefit and is similar to the 'fading' behaviour of surfers. If an intruding fisherman remains undeterred then his traps will be destroyed. ${ }^{259}$ This is similar to the vehicle damage perpetrated by surfers. Unlike in surfing, physical violence is not common among the lobster gangs. This is probably because lobstermen will rarely encounter each other while fishing. Nevertheless, lobstermen can apply very serious extra-legal sanctions. In rare cases, boats and wharfs have been destroyed during territorial disputes. ${ }^{260}$

There is variation among harbour gangs in terms of how vigorously they defend their territory. ${ }^{261}$ Some fishing areas are subject to 'mixed fishing' where more than

\footnotetext{
${ }^{254}$ Ibid 254.

255 Ibid 261.

${ }^{256}$ Ibid.

257 See ibid 267.

258 See ibid.

259 See ibid.

260 See ibid 267 n11.

261 See ibid 254, 263, 274.
} 
one harbour gang is allowed to fish. ${ }^{262}$ In contrast, other harbour gangs, especially those from island communities, claim exclusive fishing rights to all of 'their' territory and defend these rights doggedly. ${ }^{263}$ The islanders' reputation for violence is 'known the length of the coast." 264 This reputation deters intruders and is reminiscent of the reputation of the Bay Boys in California. Like the Bay Boys, the islandbased harbour gangs have created 'little fiefs carved out of the public domain. ${ }^{265}$

Some lobstermen claim that the 'differential propensity to violence' among different gangs is linked to a lack of education and exposure to the outside world among the more violent gangs. ${ }^{266}$ Acheson found that the empirical evidence did not support this claim as many islanders were well travelled and educated. ${ }^{267}$ Acheson argues that the most important factor influencing territoriality is the ability of the locals to organise. ${ }^{268}$ Many island harbour gangs are based on close kinship ties and thus are able to easily coordinate defence of their territory. ${ }^{269}$ The island harbour gangs also benefit from geography as it is more expensive for intruders to travel to the islands to fish. ${ }^{270}$ This raises the costs of intruders before they even encounter the islanders' resistance.

Surfers have also speculated that the severity of surfer localism is linked to the socio-economic status of the perpetrators. For example, Fred Pawle claims that 'conversations with old and new locals around the country found that localism peaks when the popularity of a break coincides with its surrounding suburb being at the lower end of the socioeconomic ladder. ${ }^{, 271}$ I suggest that this claim is mistaken. Of the five worst breaks in Australia, only Maroubra fits this pattern. ${ }^{272}$ In fact, the most heavily localised break in Australia, North Narrabeen, is in Sydney's wealthy northern beaches region. ${ }^{273}$ Similarly, the United States' most infamous break, Lunada Bay, is in a spectacularly wealthy location.

Acheson's study of lobsterman suggests a better hypothesis for explaining the varying severity of surfer localism. Locals are best able to defend their turf when they are sufficiently close-knit to organise a coordinated resistance. The close-knit Bay Boys provide an excellent example of this. The Bay Boys are so organised that they even delegate intimidation responsibilities within the gang. ${ }^{274}$ Coordination

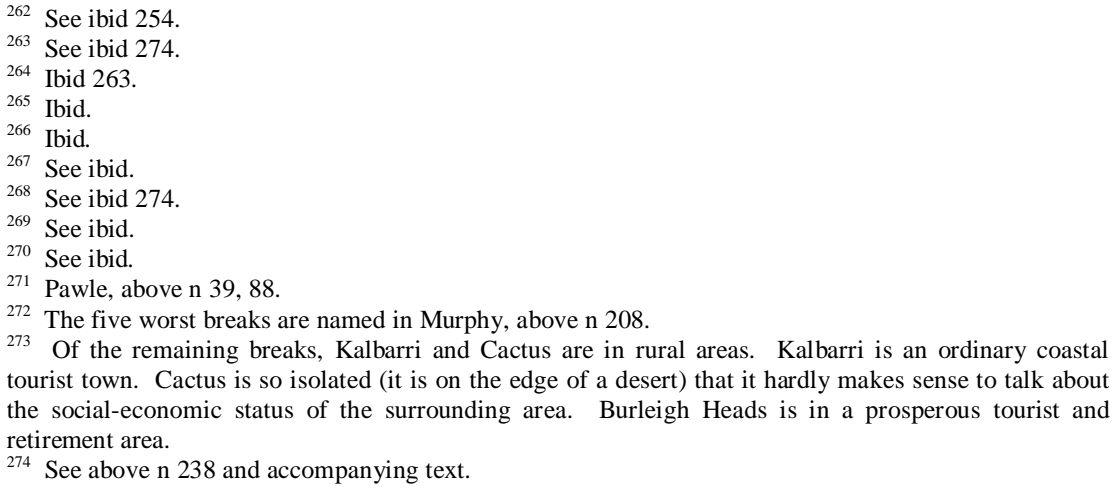


may be even more important for surfing localism than for lobstermen because physical violence is more likely. Locals will want to be sure that they will be backed up in a fight. Moreover, visiting surfers will be intimidated by the knowledge that they might meet a coordinated force.

Geography is also relevant to the ability of locals to defend their break. The cliffs of Palos Verdes help the Bay Boys defend their turf. Similarly, isolation makes a break easier to defend. The long drive to Cactus in South Australia and the boat ride to The Ranch both increase the costs for any visitors to these breaks. Visitors will also be unsettled by the knowledge that any violence would occur far from any official scrutiny. A journalist preparing a story about The Ranch discovered this when no visiting surfers would give him their names. One surfer claimed that '[i]f the Ranch surfers got mad at him ... there would be no one to protect him should they decide to exact revenge at the isolated beaches. ${ }^{275}$

The parallel between surfer localism and the lobster gangs is even more striking when one considers the different stakes involved. The lobstermen are defending their livelihood. In contrast, surfing is only a recreational activity. This suggests that the value of the resource is not the only factor determining how fiercely it is defended. Some theorists have suggested that certain lobster territories are better demarcated and defended because they have greater value as a resource than other lobster territories. ${ }^{276}$ The empirical evidence does not support this view, however. $^{277}$ Moreover, the example of surfer localism provides further reason to doubt this hypothesis. Some gangs of surfers defend their territories as vigorously as the lobstermen even though only recreation is at stake. The degree of close-knittedness of lobster and surf gangs appears to be the best predictor of how vigorously they defend their territory.

\section{G Evaluating localism}

The evils of localism are obvious. Violence and intimidation are a part of all but the mildest forms of localism. ${ }^{278}$ It is more difficult to outline the positive aspects of localism. Supporters of localism usually point to two main benefits. These benefits are improved environmental stewardship and improved 'discipline' or 'respect' in the lineup. Of these, the second provides the better justification for localism.

\footnotetext{
${ }^{275}$ Hector Tobar, 'Despite Law, Residents Tell Public To Go Away', Los Angeles Times, 29 November $1998,42$.

${ }^{276}$ See Henry E Smith, 'Exclusion Versus Governance: Two Strategies for Delineating Property Rights' (2002) 31 Journal of Legal Studies 453, 484 (discussing the view of Barry C. Field).

${ }^{277}$ See ibid.

${ }^{278}$ As I noted above, I cannot claim complete impartiality on this point having been on the receiving end of localism on a few occasions. The most serious incident occurred in Esperance, Western Australia. I was surfing alone with a group of 5 or 6 locals who clearly all knew each other. While I was paddling back out after a wave, one of the locals speared his board at me forcing me to dodge out of the way. I was then told to leave. This occurred at an isolated rural beach.
} 


\section{$1 \quad$ Private property and the environment}

Stronger forms of localism involve a quasi-proprietary claim over the waves. Thus, it makes sense to look to the usual arguments in favour of private property to see if these support localism. Two prominent arguments about the benefits of property are sometimes associated with the work of Harold Demsetz. ${ }^{279}$ First, 'property provides superior incentives for the development of resources relative to a system in which access to resources is open to all. ${ }^{280}$ Private property provides an incentive for development because it ensures that the owner can capture the fruits of any improvements made to the property. Second, private property helps prevent 'premature consumption and wasteful dissipation of resources in competition to secure the resource. ${ }^{281}$ Private property does this by internalising the costs of overuse or premature consumption.

The first argument does not provide much support for localism. The surfers' commons is difficult to improve. Apart from a very small number of artificial reefs, the surfers' commons is completely determined by weather patterns and the shape of the coastline. Thus, localism does not provide an incentive for development of the surfers' commons. In fact, rather than supporting development, localism can lead to dead-weight losses. Steve Hawk, the editor of Surfer magazine, describes a visit to Lunada Bay. ${ }^{282}$ After bravely ${ }^{283}$ travelling to the break, Hawk was amazed to find the waves completely empty:

'There was nobody around!' he recalls. 'Maybe because the waves looked pretty small by their standards, but they were big enough to get me stoked.' And alone Hawk remained that sunny spring Saturday. 'I couldn't believe it! Any other beach would have been crowded.' For the entire afternoon, he had one of the best surf beaches in California to himself. ${ }^{284}$

The Bay Boys did not notice Hawk's presence until he left the water, at which point he was confronted. ${ }^{285}$ This story suggests that the Bay Boy's monopolisation of Lunada Bay has lead to the waste of waves that break there on smaller days. It appears that the Bay Boys, who have grown used to uncontested access to Lunada's powerful waves, are not sufficiently interested in smaller days. Nevertheless, the Bay Boys' reputation is such that other surfers are afraid to take advantage of these uncrowded days.

\footnotetext{
279 See Harold Demsetz, 'Toward a Theory of Property Rights' (1967) 57 American Economic Review Papers \& Proceedings 347.

${ }^{280}$ Thomas W. Merrill, 'Introduction: The Demsetz Thesis and the Evolution of Property Rights' (2002)

31 Journal of Legal Studies 331, 331-32.

${ }^{281}$ Ibid 332.

${ }^{282}$ See Goodman, above n 191.

${ }^{283}$ See ibid ('The idea to write a column,' says Hawk, a lanky 40-year-old with wavy brown hair. 'But when I was driving up there, I was scared shitless - worried about my personal safety, afraid of being humiliated.')

${ }^{284}$ Ibid.

${ }^{285}$ See ibid.
} 
The second argument in favour of private property is more promising for localism. This argument notes that open resources are often subject to overuse and depletion. Locals themselves sometimes advance similar environmental arguments. For example, Bay Boy Peter McCollum claims that the Bay Boys are 'protecting this place [Lunada Bay] to keep it pristine for future generations. ${ }^{286}$ Indeed, Lunada Bay can be considered more pristine than many other Southern Californian surf breaks. Nevertheless, the Bay Boys cannot claim responsibility for the pristine state of Lunada Bay. In fact, the Bay Boys once built a concrete cabana for themselves at Lunada Bay. ${ }^{287}$ They were forced to tear it down after the cabana received negative news coverage. ${ }^{288}$

The environmental argument in favour of surfer localism is weakened by the unusual economics of the surfers' commons. The surfers' commons is not in danger of long term depletion like many other common resources. For example, Lunada Bay will continue to provide the same number of quality waves regardless of how many surfers try to surf there. Thus, at least from the surfer's perspective, the localism at Lunada Bay does little to safeguard the resource. Localism may minimise other externalities of surfing (such as erosion of the path down the cliff) but it does not affect the quality of the wave.

The environmental justification for localism also conflicts with the reality of surfers' environmental activism. Surfers do have a good record of environmental activism. Surfer organisations arrange regular beach clean-ups and have participated in environmental impact litigation. These activities are not usually organised by groups of locals such as Bay Boys. Rather, surfer environmentalism is mostly organised by large organisations such as The Surfrider Foundation and the Groundswell Society. ${ }^{289}$ The Surfrider Foundation is an international organisation of surfers with over 37,000 members. ${ }^{290}$ The Surfrider Foundation has organised beach cleaning, water quality testing, environmental protests and has established environmental education programs and scholarships. ${ }^{291}$ The foundation has also been the plaintiff in some important environmental law cases. ${ }^{292}$ Moreover, rather than being a

\footnotetext{
${ }^{286}$ Kew, above n 169, 114.

${ }^{287}$ See Fringe Benefits, above n 192.

${ }^{288}$ See ibid.

${ }^{289}$ For a description of the activities of The Surfrider Foundation see their website at www.surfrider.org. The Groundswell Society also has a website available at www.groundswellsociety.org.

${ }^{290}$ See Surfrider Foundation, Surfrider Foundation Achievements

<http://www.surfrider.org/achievements.asp> at 25 March 2004.

${ }^{291}$ See ibid.

${ }^{292}$ See ibid. The Surfrider Foundation has also participated in litigation as amicus curiae. See Brief for Natural Resources Defense Council, Sierra Club, Coast Alliance, Amigos de Bolsa Chica, Coaast, Committee for Green Foothills, Concerned Citizens to Save Oxnard Shores, League for Coastal Protection, Marin Conservation League, Planning and Conservation League Foundation, Scenic Shoreline Preservation Conference, Inc., and Surfrider Foundation as Amici Curiae, Nollan v California Coastal Commission, 483 US 825 (1987) (No. 86-133).
} 
product of localism, the Surfrider Foundation has organised activities against surfer localism. $^{293}$

Overall, I believe we should be very sceptical of environmental arguments in favour of localism. The activities of The Surfrider Foundation show that surfers can play a positive role in the environment through more formal self organisation. Exclusionary locals appear to be using the environmental argument as a cover for their actions. As Mike Kew wrote in response to the claim that the Bay Boys are protecting Lunada Bay for future generations: 'What future generations? The Bay Boys' kids but no-one else's? A public California beach-cum-private Palos Verdes Estates fraternity? ${ }^{294}$

\section{$2 \quad$ Localism as sustaining cooperative norms}

Another argument for localism is that it helps ensure that the cooperative norms of surfing are obeyed. ${ }^{295}$ This is a more compelling justification for localism. Some theoretical points about norms help to illustrate this. While most commentators believe that norms are welfare maximising for groups this does not mean that individuals maximise their welfare by following norms. Rather, the fact that norms are not individually rational gives norms the power to solve collective action problems. ${ }^{296}$ Norms can impose costs on individuals in two ways. First, following the dictates of a norm can be costly (such as when a rancher agrees to pay for the damage done by errant cattle despite the lack of legal liability). Second, enforcing norms can impose costs as sanctioning can lead to retaliation or entrench noncooperation. $^{297}$

This raises the question as to why individuals would enforce norms. McAdams notes that the individual costs of norm enforcement raise a second-order collective action problem: '[I]f others enforce the norm, the individual can gain the norm's benefits without bearing enforcement costs; if others do not enforce the norm, the individual's solo efforts are wasted.'298 Thus, we may wonder 'why individuals will ever begin to sanction violators or why threats of sanctions are ever credible. ${ }^{299}$

\footnotetext{
${ }^{293}$ See, for example, Kevin Cody, 'DA gets Banas case while Banas plans PVE, gang suit', Easy Reader, 14 February 2002,

<http://easyreader.hermosawave.net/news2002/storypage.asp?StoryID=20020213\&IssueDate=2/14/200> (quoting a Surfrider press release).

${ }^{294}$ Kew, above n 169, 114.

${ }^{295}$ See Barilotti, above n 40

${ }^{296}$ See generally, Dan M Kahan, The Logic Of Reciprocity: Trust, Collective Action, and Law <http://papers.ssrn.com/abstract=361400> at 28 April 2004 (Public Law and Legal Theory, Research Paper No. 31) (discussing the power of cooperative norms to solve collective action problems and noting that people often observe such norms).

${ }^{297}$ I noted above that second-party sanctions in surfing are particularly costly as they can lead to violent retaliation. See Part IV(C).

${ }^{298}$ McAdams, above n 34, 352

299 Ibid.
} 
This second-order collective action problem is especially pressing for surfers as the face-to-face sanctions used by surfers are very costly because they risk provoking a violent response. ${ }^{300}$ Surfer localism may provide a solution to this problem. Localism (even in its milder forms) may provide locals with an incentive to enforce the background norms of surfing. Consider the following discussion of localism from Surfline's Bill of Rights and Lefts:

The Core Local should at all times understand that other surfers have a right to ride at the spot he knows so well, and that his enhanced knowledge of the break gives him a responsibility as much as a reward. His responsibility involves leading the wave-sharing rhythm; keeping an eye on surfers who look like they might get into trouble; putting a lid on any bullying of kids by older surfers; and providing an example to the grommets and beginners of how to behave in a wide range of surfing circumstances. Taking care of these responsibilities will guarantee the reward (uninterrupted choice of the best set waves). Ignoring them and taking the reward anyway will guarantee ongoing ill-feeling in the lineup. ${ }^{301}$

This passage suggests that locals earn a reward for policing a break. This reward comes in the form of priority over the best waves. This may solve the second-order collective action problem by ensuring that some surfers at a break have an incentive to ensure that the norms of surfing are being followed.

Localism may also help ensure that cooperative norms are followed by increasing the value of a good reputation and by reducing transaction costs of communication. The 'dues paying' requirement of localism encourages surfers to devote time to a single break and to build long term reputations. This gives surfers an incentive to show that they are willing to observe the rules of the road like the drop-in rule. Also, localism can make norm enforcement easier simply by reducing the number of surfers at a break. A surfer or a group of surfers interested in 'policing' a break through third-party sanctions will obviously have an easier time policing a smaller group.

These justifications for localism are not fully persuasive. First, many surfers are willing to sanction others, even violently, outside of the context of localism. ${ }^{302}$ Thus, it is unclear to what extent localism is required for the norms to successfully regulate behaviour. Also, it may be that a surfer will be more likely to observe the rules of the road at a crowded break because there are more surfers present who may decide to sanction misbehaviour. Moreover, once it is accepted that locals can

\footnotetext{
300 See Part IV(C).

${ }^{301}$ Bill of Rights, above n 57 (discussing rule 8 'Don't use your surfing advantages to abuse your fellow surfer').

${ }^{302}$ Recall my recent experience in Narragensett discussed above at note 189 . There I witnessed someone receive a violent sanction for violating the drop-in rule. Narragansett Town Beach is generally considered to be free of localism. See Surfline, Surfline: Travel: US: Southern New England: Narragansett Town Beach <http://www.surfline.com/travel/surfmaps/us/so_new_england/town_beach.cfm> at 28 April 2004 (giving Town Beach a rating of 'none' for the 'local vibe').
} 
get priority over visitors then locals may become tempted to start practicing stronger forms of localism and start excluding visitors altogether. It is unclear whether the enforcement benefits of milder forms of localism justify the risk of the emergence of stronger forms of localism. Nevertheless, it is plausible that localism helps solve the second-order collective action problem with respect to the enforcement of surfing's cooperative norms.

\section{$3 \quad$ Localism versus severe overcrowding}

A defender of localism might claim that I dismissed the environmental argument in favour of localism too quickly. The defender will claim that there is a danger of permanent degradation of the surfers' commons. This degradation comes in the form of regular overcrowding so extreme that surfing becomes difficult for everybody at the break. The local will claim that intimidation by locals is required to keep the crowds at some breaks to a manageable size.

The defender of localism is correct to note that severe crowding can ruin surfing for everybody. Consider the following description of a crowded day at Kirra Point on Queensland's Gold Coast:

[Mark Rabbidge], his wife Pam Burridge, son Michael and mate Peter Townend recently surfed Kirra Point on a good day, when the crowd was ridiculously thick. . . 'Within 20 minutes the four of us were back on the beach,' [Mark] says. 'We were all saying you can't ride it. There's too much flotsam and jetsam in the way. And we're all capable surfers - two of us were former world champions. . . . You simply couldn't ride the wave for all the people in the way. ${ }^{, 303}$

Clearly, when world champions cannot even ride the wave, crowding has become unmanageable. A day of extreme crowding is a temporary tragedy of the commons. If these crowds return day after day then surfers will be wasting a break. If localism can prevent this then it may be justified as preventing a tragedy of the commons after all.

Dwayne Harris, a local from Burleigh Heads (another Gold Coast surf break near Kirra Point), claims that Burleigh's heavy localism helps to control the crowds. He says:

[A] few guys get angry and get into fights, but you need that, you need that out there. After you see a good bit of biffo [fighting] go down, the lineup clears itself a bit. . . . It really needs it some days. You need a fight to sort it out. ${ }^{304}$

\footnotetext{
303 Pawle, above n 39, 93.

304 Rielly, above n 151, 43.
} 
Dwayne contrasts the situation at Burleigh to Kirra, claiming that 'at Kirra there's [sic] locals but they don't police it anymore. ${ }^{305}$

There are two reasons to believe that localism cannot be justified as a way to prevent extreme overcrowding. First, it is important to note that localism does not seem to be causally linked to this threat. As noted above, heavy localism appears to be most closely linked to the close-knittedness of those that practice it. ${ }^{306}$ Admittedly, heavy localism is practiced at Narrabeen, Burleigh and Lunada Bay where high quality waves and nearby cities ensure that severe overcrowding is a threat. Nevertheless, heavy localism is also found at many locations where severe crowding is highly unlikely. For example, Oregon and Washington are both known for heavy localism. ${ }^{307}$ Cold water and large distances from major population centres mean that the waves in Oregon and Washington will never get nearly as crowded as those in Southern California. Thus, while heavy localism is aimed at discouraging other surfers and keeping crowds down, it is not limited to locations where severe crowding is a threat. Second, and more importantly, localism fails right at the point where it is needed most. This is because any overcrowding that is sufficiently severe to ruin a break will overwhelm the resources of localism. Thus, localism fails right where it is needed most.

Crowds of new surfers can arrive every day at easily accessed breaks close to large population centres. The locals will have to engage in daily intimidation of hordes of new people if they want to keep the crowds down. The costs of this exercise will increase rapidly with larger crowds. As a result:

[T] he hard-line localism of yesteryear - where a small, close-knit crew of regulars uses such intimidation to keep outsiders at bay - is fast becoming extinct. The sheer number of surfers in the water these days makes policing the line-up a bootless exercise. ${ }^{308}$

This suggests that surfers should look for other solutions if they wish to prevent extreme overcrowding. ${ }^{309}$

It might be objected that heavy localism has survived at some urban breaks such as Lunada Bay. The Bay Boys do not have to continually intimidate new visitors because few visitors dare to surf there. ${ }^{310}$ This appears to be a result of the reputation they have built through their extreme tactics. ${ }^{311}$ Nevertheless, the Bay Boys are an unusual case. Their extreme tactics survive in an environment where the local non-surfing community tolerates their behaviour and the police pay them little

\footnotetext{
305 Ibid, 42.

306 See Part V(F).

${ }^{307}$ See, for example, Salkever, above n 188 (noting that '[i]n Oregon and Washington, local surfers regularly escort nonlocal surfers from the water at prized surf breaks').

${ }^{308}$ Barilotti, above n 40.

309 In Part VI(B) I discuss other ideas such a permit system.

${ }^{310}$ See Goodman, above n 191.

311 See ibid.
} 
attention. ${ }^{312}$ Also, the cliff at Lunada Bay makes the break easier to defend. Heavy localism has not prevented crowding at most urban breaks.

Locals at crowded breaks may still be able to exclude less favoured groups of surfers. Locals at the crowded urban break of Trigg Point in Perth exclude bodyboarders and wave-ski riders. ${ }^{313}$ Longboarders are excluded at some breaks in the Santa Cruz area. ${ }^{314}$ This more limited intimidation is probably easier to achieve because fewer surfers need to be excluded and the remaining surfers will benefit from the practice and may offer tacit support.

The exclusion of less favoured surf craft is a hybrid of an 'exclusion strategy' and a 'governance strategy' in the sense outlined by Henry Smith. ${ }^{315}$ An exclusion strategy is based on restricting access to a resource while a governance strategy manages a common resource by regulating individual activities rather than access. ${ }^{316}$ Under a hybrid strategy, access is denied 'on the basis of features or activities of the potential entrant. 317 An example of a hybrid strategy in communal fishing grounds would be 'rules that exclude anyone with a certain type of gear (for example, a net as opposed to a line). ${ }^{318}$ The exclusion of longboarders and wave-ski riders is very similar to this kind of regulation in fishing. Just as nets can make catching large numbers of fish easier, the increased paddle speed of longboards and wave-skis makes catching waves easier. Thus, locals concerned about the effects of crowding often start by excluding the surfers who are the biggest threat to their waves. Of course, a horde of longboarders will not cause permanent depletion of the surfers' commons in the way that net fishing could destroy a fishery. Thus, surfers who exclude longboarders are looking out for more immediate interests. Nevertheless, by excluding less favoured groups of surfers, locals can mitigate the effects of severe overcrowding.

\section{$4 \quad$ Cash localism}

Cash localism raises its own theoretical issues. This form of localism can be divided into two subclasses. First, there is localism that is simply tied to the ownership of land. This is the localism practiced at the Hollister Ranch. Second, there is cash localism that is tied to ownership plus development. This kind of localism is found in Tuvarua and some other 'surf resorts'. I evaluate these subclasses of cash localism separately.

\footnotetext{
312 See Part VI(B)

313 See above $\mathrm{n}$ 183-85 and accompanying text.

${ }^{314}$ See McHugh, above n 2 ('[t]hese days, in Santa Cruz, if you even paddle out on the wrong-size surfboard, guys tell you to leave')

${ }^{315}$ See Henry E Smith, 'Exclusion Versus Governance: Two Strategies for Delineating Property Rights' (2002) 31 Journal of Legal Studies 453.

316 See ibid, 468-70.

317 Ibid, 470 .

${ }^{318}$ Ibid, 470 n54.
} 
Ordinary surfer localism centres on the close ties between the locals. This is shown by the requirement that an aspiring local spend a lengthy period paying dues and showing deference to the more established locals. The cash localism of the Hollister Ranch is different because it allows a new property owner to become a local instantly. Thus, it might seem that cash localism would be harder to maintain because the locals will not have the close bonds formed through the dues paying process. Nevertheless, Ranch localism is considered to be very successful and fierce. This needs to be explained.

Two factors explain the success of Ranch localism. First, by using ownership of property as the barrier for entry the locals are able to keep exclusion costs much lower than most other groups of locals. By banding together as property owners, Ranch surfers have removed all land access to the surf. This will help compensate for any loss of close-knittedness among the locals. Second, the purchase of property demonstrates a long term commitment to the area. Typically, locals will not know if a new visitor intends to devote time to a new break. Thus, it would make no sense to immediately accept a new visitor as a local. In contrast, when a new owner paddles out for the first time at the Ranch, he or she has paid at least $\$ 125,000$ for the privilege. Thus, Ranch locals can have confidence that the visitor is in it for the long haul.

Is Ranch localism better justified than ordinary surfer localism? The Ranch is widely acknowledged to contain some of California's best preserved coastline. Even excluded surfers begrudgingly admit this. As Nick Carroll writes: 'The Ranch smacks of nasty elitism, but in fact it works: the coastline remains pristine, and a good day's surfing there is filled with an extraordinary sense of serene beauty. ${ }^{, 319}$ Nevertheless, the pristine state of the Ranch cannot be credited to surfer localism. The Ranch owners exclude everybody, not just surfers. In fact, the owners have been waging a long and bitter battle against attempts to improve public access to that part of the coast. ${ }^{320}$ As a result of this intransigence, The Ranch is one of the few places specifically named in the California Coastal Act, a law intended to guarantee public access to the state's coastline. ${ }^{321}$ Decades after this law was enacted, owners at The Ranch are still able to exclude visitors. ${ }^{322}$

Thus, surfer localism is only a small part of any explanation of the pristine state of The Ranch. The Ranch's owners use the tactics of surfer localism to extend their property rights into the public domain but it is their land-based property rights that best explain the pristine environment. Surfer localism only helps discourage boaters and these visitors are not likely to cause extensive damage to the Ranch coast-

\footnotetext{
319 Carroll, above n 144, 63. Dean Kronman described the coastline at the Ranch as 'sublimely beautiful.' Anthony Kronman, Personal communication February 2004.

321 'It is the intent of the Legislature that the State Coastal Conservancy and the State Public Works Board utilize their authority provided under law to implement, as expeditiously as possible, the public access policies and provisions of this division at the Hollister Ranch in Santa Barbara County.' CAL. PUB. RES. CODE $\$ 30610.8$ (2004) (this provision was added to the Coastal Act in 1982).

${ }^{322}$ Tobar, above n 275.
} 
line. Moreover, as explained above, the visiting surfers will not deplete the supply of waves as this is a resource unaffected by overuse.

The localism practiced at surf resorts is unique because it is tied to commercial development. I argued above that localism is not supported by the usual arguments advanced in favour of property rights. These arguments are based on a claim that the long term incentives created by property rights encourage both development and good environmental management. ${ }^{323}$ I argued that these claims are weak when applied to localism because the surfers' commons cannot be improved through development and is not threatened with permanent depletion. Surf resorts may be a counter-example to my argument. The ability to claim a property right over a surf break could be an important factor motivating a tourist development. Of course, this development will not improve the quality of the surf break. Nevertheless, the development may improve the local economy. Thus, this form of cash localism does not help surfers but it could be good for non-surfing local residents. This conclusion is supported by the observation that this form of localism is enforced by non-surfing local tribes rather than by surfers.

\section{RESPONSES TO LOCALISM}

The battle for the soul of surfing is captured in a story about some graffiti in Byron Bay, Australia. Following the lead of locals all around the world, local surfers had painted 'Locals Only' near The Pass surf break. ${ }^{324}$ In response, the graffiti was altered to read 'Love Only. ${ }^{, 325}$ This Part reviews attempts to encourage cooperation in the surf and to prevent the worst aspects of surfer localism.

\section{A Norm reinforcement}

As noted above, many theorists believe that norms offer a powerful and cheap way to solve collective action problems. ${ }^{326}$ Some commentators also suggest that norms are highly changeable and that norms can be changed through intentional intervention. ${ }^{327}$ Taken together, these points suggest that norms can be a useful tool of public policy. The tag 'New Chicago School' has been applied to the theorists who suggest that the intentional manipulation of norms is a way to achieve social policy goals. $^{328}$

\footnotetext{
323 See Part $(\mathrm{V})(\mathrm{G})(1)$.

324 See Murphy, above n 208.

325 See ibid.

${ }^{326}$ See above n 114-16 and accompanying text

327 See, for example, Posner, above n 34, 772-74; Sunstein, above n 115, 929-30.

328 See Ellickson, above n 26, 548-49 (identifying Dan Kahan, Cass Sunstein and Lawrence Lessig as members of this school).
} 
Intentional manipulation of norms can come from private actors or from government. ${ }^{329}$ Members of the New Chicago School are supportive of government intervention. $^{330}$ Governments can influence norms through education, persuasion, incentives such as taxes or outright prohibition. ${ }^{331}$ The government may also be able to influence norms through the so-called 'expressive power' of law. ${ }^{332}$ In opposition to these views, Eric Posner is sceptical of the power of governments to effect positive change though changing social norms. Posner suggests that positive change is more likely to come from nongovernmental movements. ${ }^{333}$

Surfing is not of much concern in Chicago. Nevertheless, the general idea of the New Chicago School has been applied to the surfing world. As surfing is almost entirely governed by informal norms an obvious response to any problems (such as increased violence in the surf) would be to try to change or reinforce norms. In fact, both governmental and nongovernmental organisations have explicitly tried to influence surf norms. The surfing community has responded to the worst aspects of localism by attempting to reinforce the healthy surfing norms. These efforts have included posters and signs near breaks, educational efforts and even law school conferences.

Surfline's Bill of Lefts and Rights is an attempt to educate surfers about the cooperative norms of surfing. ${ }^{334}$ Surfline's website is one of surfing's most popular media sources receiving approximately one million unique visits per month. ${ }^{335}$ After the editors at Surfline began to receive many enquiries about surf etiquette they decided to provide a reference for new surfers. ${ }^{336}$ Their account of surf etiquette was developed by a group of Surfline editors and was intended to be 'mostly observational of what's really out there but with an optimistic perspective. ${ }^{337}$ They hope that their site will educate new surfers and help them avoid conflict. ${ }^{338}$

Other attempts to educate surfers about surf etiquette have come from the Surfrider Foundation. While the 'core business' of the Surfrider Foundation remains marine conservation, ${ }^{339}$ the foundation has responded to surfing violence and localism in Australia and the United States. ${ }^{340}$ In Australia, the foundation has prepared posters and plaques explaining the cooperative norms of surfing and has placed these

\footnotetext{
329 See Sunstein, above n 115, 947

${ }^{330}$ See, for example, Lawrence Lessig, 'The New Chicago School' (1998) 27 Journal of Legal Studies 661, 666-70.

331 See Sunstein, above n 115, 947-52.

332 See ibid, 964-65.

333 See Posner, above n 34, 798

334 See Telephone interview with Marcus Sanders (8 March 2004).

335 See ibid.

${ }^{336}$ See ibid.

337 Ibid.

${ }^{338}$ See ibid.

339 See Surf Forum 1, above n 43, 246 (commentary by Neil Lazarow, National Project Director and President of Eastern Beaches Branch of Surfrider Foundation Australia).

${ }^{340}$ See ibid, 240-47; Cody, above n 293.
} 
plaques at a number of popular surf breaks. ${ }^{341}$ Similar plaques have also been placed at some breaks in the United States. ${ }^{342}$

Surfrider has even responded to localism in Palos Verdes. After a well publicised assault on a visiting surfer, the local Surfrider chapter organised a 'peaceful, non violent surfing session, paddle-out and beach clean-up to show our surfing community's commitment to putting an end to Palos Verdes localism. ${ }^{343}$ This event took place at a break known as Indicators which is notoriously localised by another gang of Palos Verdes surfers known as the Dirty Underwear Gang. ${ }^{344}$

Support for surfing's cooperative norms has even come from a law school. Australia's Southern Cross University has organised two forums on the 'Law of the Surf' ${ }^{345}$ Participants at the forums were concerned that formal legal regulation might arise if surfers fail to apply their informal norms. 'The objective of the Law of the Surf Forum was to promote the universally accepted lore of surfing recognised by the surfing community so that surfing remains free of government regulative intervention and preserves the Free Spirit of Surfing. ${ }^{346}$ Justice Greg James of the Supreme Court of New South Wales claimed that ' $[t]$ he responsibility for regulating the surf should be on those using the surf . . . [t] he consciousness that it needs to be done, or the law will regulate it for us, has got to be expanded. ${ }^{347}$

The City of Santa Cruz provides a rare example of a government attempt to reinforce the cooperative norms of surfing. ${ }^{348}$ The City is planning to distribute brochures explaining the cooperative norms of surfing. ${ }^{349}$ Nevertheless, the general consensus among surfers is that norm reinforcement will not succeed without grassroots support from surfers. ${ }^{350}$ This may explain why most attempts to support surfing norms have come from private organisations. Also, surfers' hostility to formal regulation ${ }^{351}$ may explain their preference for privately organised campaigns of norm reinforcement.

\section{B Existing law}

Heavy localism relies on tactics, such as threats, property damage and violence that are subject to criminal sanctions. Thus, shouldn't existing criminal law provide the best response to the worst aspects of localism? Criminal law has proved inadequate

\footnotetext{
${ }^{341}$ See Surf Forum 1, above n 43, 240-47 (commentary by Neil Lazarow).

342 See Telephone interview with Marcus Sanders (8 March 2004).

343 Cody, above n 293 (quoting a Surfrider press release).

344 See ibid.

${ }^{345}$ See Surf Forum 1, above n 43; Surf Forum 2, above n 1.

${ }^{346}$ Surf Forum 1, above n 43, 228.

347 Ibid (commentary by Justice Greg James).

${ }^{348}$ See McHugh, above n 2.

349 See ibid.

${ }^{350}$ See Surf Forum 1, above n 43, 24 (commentary by Neil Lazarow) ('[i]ts [sic] all very well developing a poster and going [sic] 'here guys have a look', but its [sic] important to get as much grass roots support for it as possible').

${ }^{351}$ See Part VI(C).
} 
for a number of reasons. These include underreporting by victims of localism, the difficulty of prosecution, jury sympathy for white middle class defendants and police inattention and complicity. Together, these factors have made criminal law relatively ineffective. Nevertheless, there is some evidence that surfers may be deterred if they perceive a credible threat of prosecution for violent activity.

California provides a number of examples of surfers facing criminal sanctions for localism violence. ${ }^{352}$ The following example from San Francisco's Fort Point is illustrative. Fort Point is one of the world's most photogenic surf breaks. The waves there peel along a rocky point directly underneath the Golden Gate Bridge. Fort Point is a challenging break to ride and is also notorious for localism and violence. On March 28, 2002, Adam Browning arrived at Fort Point for an after work surf. ${ }^{353} \mathrm{He}$ was immediately confronted and assaulted by three surfers. ${ }^{354} \mathrm{He}$ was badly beaten and even held underwater leading him to fear for his life. ${ }^{355}$ After being assaulted in the water Browning emerged from the surf "with a broken nose, a gash over one eye and bruises all over his body. ${ }^{356}$ A tourist caught the assault on tape. 'The tape's last images are vivid. Browning has struggled to shore. He sits on rocks, dazed. [Ryan] Farrell comes up, shouts, then rams his fist straight into Browning's face. ${ }^{357}$

Browning's attackers were arrested by federal park police. ${ }^{358}$ Ryan Farrell and Yoel Gorfain pleaded to misdemeanour assault charges. ${ }^{359}$ When sentencing Farrell, the magistrate judge noted that Farrell's behaviour had deterred other surfers from visiting Fort Point:

'That [video] was hard to watch,' magistrate judge James Larson told Farrell. 'It's hard to imagine any reasonable circumstance that would lead to that kind of rage. ... You disgraced yourself and your family not only in this but in other incidents. You became a virtual legend. I've heard that women don't go there (Fort Point) to surf because of people like you. ${ }^{, 36}$

Despite these harsh words, none of Browning's attackers received custodial sentences. $^{361}$ This is consistent with a general trend of light sentences for localism violence. $^{362}$

\footnotetext{
352 See, for example, Kew, above n 169, 105-10.

353 See McHugh, above $\mathrm{n} 2$.

354 See ibid.

355 See ibid.

356 Ibid.

357 Ibid.

${ }^{358}$ See ibid.

359 See ibid.

360 Ibid.

361 See ibid.

${ }^{362}$ See Kew, above n 169, 105-10 (discussing the light penalties metered out to surfers convicted of violent acts in San Diego).
} 
An interesting aspect of the Fort Point case, and of some other criminal prosecutions of surfers, is the creative use of probation conditions to keep perpetrators away from the breaks they terrorise. Ryan Farrell was prohibited from visiting any Bay Area beaches on federal land for three years. ${ }^{363}$ After a conviction for localism violence in Los Angeles, David Ortega was jailed for five days and prohibited from surfing his local break for three years as a condition of his probation. ${ }^{364} \mathrm{He}$ was caught surfing a few days after his sentencing and spent 6 months in jail as a result. $^{365}$

The incident at Fort Point was unusual in that it was captured on video, making prosecution relatively easy. ${ }^{366}$ Most intimidation by locals is not captured on video nor reported to authorities. ${ }^{367}$ Recall that locals often rely on threats to deter visiting surfers. ${ }^{368}$ This low level intimidation is almost never reported because surfers realise that prosecution would be almost impossible. ${ }^{369}$ Similarly, violent actions that do not result in injury (such as an attempt to spear another surfer with a board) are very rarely reported. ${ }^{370}$ Police and lifeguards tend only to see only a subset of the most serious cases involving physical injury. ${ }^{371}$ This makes responding to localism very difficult.

In Palos Verdes, visiting surfers have alleged that the local police department turns a blind eye to violence by the local surf gangs. After being assaulted at the Palos Verdes break known as Indicators, Timothy Banas brought a civil suit against members of the 'Dirty Underwear Gang'. ${ }^{372}$ Banas also sued Palos Verdes Estates alleging:

[T]he Palos Verdes Estates Police Department has a custom and practice of ignoring complaints made to it by victims of crime perpetrated by the Dirty Underwear Gang. . . . In many cases ... the Palos Verdes Estates Police Department threatened and intimidated victims not to press charges against members of the Dirty Underwear Gang. . . . [The Department] allows the Dirty Underwear Gang to use and claim the surfing locations described herein as their own property and allows the building of nonpermitted buildings, shacks, concrete changing areas and barbecue pits on public land by the Dirty Underwear Gang for their sole use. The Palos Verdes Police Department, or at least a substantial number of its officers,

\footnotetext{
${ }^{363}$ See McHugh, above $\mathrm{n} 2$.

${ }^{364}$ See Kew, above n 169, 117.

365 See ibid.

366 See McHugh, above n 2 ('[e]xperienced surfers say only two things made this event unique: It was caught on tape, and convictions were actually sought').

367 See Telephone Interview with Chris Brewster (14 November 2003).

368 See above n 170-75 and accompanying text.

369 See Telephone Interview with Chris Brewster (14 November 2003).

${ }^{370}$ See ibid.

371 See ibid.

${ }^{372}$ See Complaint, Banas v Palos Verdes Estates (on file with author, provided by Banas' attorney Mike Sisson).
} 
view the Dirty Underwear Gang's activities as helpful to them in being 'proactive' and keeping 'undesirables' out of their city. ${ }^{373}$

Unsurprisingly, the police denied these claims. ${ }^{374}$ Police Chief Timm Browne claims that 'the city has responded [to localism] by aiming a surveillance camera at the surf break and briefly had undercover cops, posing as outsiders, paddling into the lineup. ${ }^{375}$

While these recent actions from the police are an improvement, they seem mainly to be a response to recent bad publicity. ${ }^{376}$ Violent localism has been a serious problem in Palos Verdes for decades. Moreover, the Palos Verdes Police Department has encountered community opposition to their increased attention to surfer localism. ${ }^{377}$ The Bay Boys went door-to-door in Palos Verdes to mobilise the community against the surf cameras. ${ }^{378}$ The first camera was placed at Indicators but the city had plans to add another camera at Lunada Bay itself. ${ }^{379}$ The camera at Indicators was provided free by Surfline who published its images on the web. The proposed camera at Lunada Bay was to be sponsored by the Surfrider Foundation and was also to be available on Surfline's website.

The Bay Boys claimed that these cameras would lead to 'an impending crush of surfers who would clog residential streets, strip naked as they changed into wetsuits, urinate in bushes and leave trash. ${ }^{380}$ The affluent residents were swayed by these concerns and subsequent community pressure lead to the removal of the cameras. $^{381}$ Thus, it appears that, in Palos Verdes at least, the non-surfing community shares the local surf gangs' hostility to visitors and is willing to help undermine police efforts to crack down on localism violence. In such an environment, it is hardly surprising that visiting surfers do not believe that local authorities will vigorously pursue complaints against the surf gangs.

While criminal enforcement has tended to be ineffective against localism, the possibility of criminal sanctions may deter the some violence. Burleigh Heads local Dwayne Harris claims that increased enforcement has lead to a reduction in violence at his break. He claims that '[i]t was worse in the '70s and '80s, the laws were a lot more lax then ... [t]hese days you can't hit people. ${ }^{382}$ Similarly, the threat of criminal sanctions moderates the actions of locals at Maroubra, New South

\footnotetext{
373 Ibid.

${ }^{374}$ See Alan Gathright, 'Santa Cruz Tries to Tame Surfing Wars: Brochure Spells Out Unwritten Etiquette for Dropping in on a Wave', The San Francisco Chronicle, 4 March 2003, A15.

375 Ibid.

${ }^{376}$ See Kew, above n 169, 112-15 (describing an incident where a TV crew captured acts of violent localism at Lunada Bay).

${ }^{377}$ See Kenneth R Weiss, 'Angry Residents Sink Police Chief's Surf Cam; Beaches: Images are Taken Off Web Over Fear of Luring Crowds to Palos Verdes', The Los Angeles Times, 7 June 2002, A1.

378 See ibid.

379 See ibid.

380 Ibid.

381 See ibid.

382 Pawle, above n 39, 96
} 
Wales. The locals there (known as the 'Bra Boys') will still fight with visitors but 'the fight's usually over when the victim hits the ground. ${ }^{, 383}$ Bra Boy Jai Abberton explains that '[s]ome of the boys have done time . . . so they're not going to jump on a bloke because it's not worth the risk [of being charged with assault and sent back inside]. ${ }^{384}$ Thus, it appears that, even if it cannot defeat localism, criminal law may be able to deter its worst excesses so long as the locals have a genuine fear of enforcement. So, while the breaks like Lunada Bay are never likely to be welcoming places, it may be that the police could protect visitors from the risk of serious assault.

\section{Legislative proposals / regulation}

The limitations of existing criminal law led Chris Brewster, San Diego's chief lifeguard, to propose a law, called the California Open Waves Act ('Waves Act'), specifically aimed at controlling surfer localism. ${ }^{385}$ Chris Brewster's original idea was to create a new law criminalising any intimidation aimed at excluding others from a surf break. ${ }^{386}$ After consulting with a local assistant district attorney, he modified the proposal. ${ }^{387}$ The final proposal contained two elements. ${ }^{388}$ First, it

\footnotetext{
383 Ibid 87.

${ }^{384}$ Ibid 87 (alteration in original). Unfortunately, it appears that the deterrence of criminal law has not worked with Jai Abberton. He has since been charged with (a non-surfing related) murder. See 'Bra Boy Surf Star Committed for Trial', Sydney Morning Herald, 15 October 2004.

385 See Telephone Interview with Chris Brewster (14 November 2003); Kew, above n 169, 109-10.

386 See Telephone Interview with Chris Brewster (14 November 2003).

387 See ibid.

388 See California Open Waves Act (on file with author, provided by Chris Brewster). The complete proposed Waves Act read as follows:

California Open Waves Act
}

(1) This shall be known as the California Open Waves Act.

(2) The State of California hereby declares that the ocean along California's coastline and the waves which strike it are an invaluable asset which is owned by no person and available for equal use by all. While activity zones and special event areas may be established by the state and local governments, no person, regardless of residence, lineage, social status, or other reason may lawfully claim the right to a wave, waves, or wave break area along the California coastline. The surf belongs equally to everyone.

(3) Except as noted in subsection (4) of this section, for any conviction of Penal Code Sections 242/243, $422 / 17$ (b)(4), or 415 wherein the act was accomplished during an attempt to intimidate or prevent another person from exercising lawful use of ocean resources, including but not limited to surfing, fishing, swimming or diving, the sentence, should probation be granted, shall include a mandatory period in custody of the Sheriff of not less than 30 days for a first offense.

(4) For any conviction of Penal Code Sections 242/243 or 245(a)(1) wherein the act was accomplished while the victim was physically in a water environment, including the ocean, lake or river, the sentence, should probation be granted, shall include a mandatory period in custody of the Sheriff of not less than 60 days for a first offense.

(5) For any subsequent conviction covered under subsection (3) or (4) of this section, probation shall not be granted.

(6) Pursuant to Section 245, a surfboard is a deadly weapon when used in an attempt to injure another person.

(7) In addition to any other penalty prescribed as a result of a conviction under this act, the person so convicted shall, as part of the conviction, be required to remain out of the area within no less than 1,000 yards of the offense for a period of no less than one year. 
included an expressive declaration that the "the surf belongs equally to everyone., 389 Second, it toughened penalties for the existing crimes of battery and threatening 'wherein the act was accomplished during an attempt to intimidate or prevent another person from exercising lawful use of ocean resources. ${ }^{390}$ The Waves Act provided for a minimum sentence of 30 days custody for a first offence or 60 days for a battery occurring in the water. ${ }^{391}$ The Act also declared a surfboard a deadly weapon 'when used in an attempt to injure another person.,392

Brewster sent the proposed Waves Act to the City of San Diego's 1999 legislative sponsorship program. ${ }^{393}$ Brewster had previously convinced the city to propose new state law and he is the original drafter of a number of California laws such as the California Boating Safety Act of $1999 .^{394}$ In this case, Brewster suggested that local surfing organisations could be enlisted to support the Waves Act. ${ }^{395}$ Brewster also predicted that the proposal would receive positive coverage in the surf media. ${ }^{396}$ These two predictions turned out to be completely incorrect. ${ }^{397}$ The proposal received quite negative coverage in the surf media and was very poorly received in the surf community. ${ }^{398}$ With the proposal lacking support, the City of San Diego decided not to sponsor the Waves Act and it never even got a hearing in Sacramento. ${ }^{399}$

Chris Brewster underestimated the surfing community's hostility to the formal regulation of surfing. This attitude appears to be almost universal among surfers. I encountered many expressions of opposition to regulation while researching this article. $^{400}$ This attitude is not simply anti-lawyer prejudice. The participants at the University of Southern Cross's forums about surfing, many of whom were lawyers or judges, also expressed hostility to the idea of formal regulation of surfing. ${ }^{401}$ Surfers' hostility to regulation is reminiscent of the attitudes of Acheson's lobstermen. Acheson noted that the lobstermen tend to believe that 'the government has

(8) For purposes of this section, surfing means riding a naturally occurring ocean wave or otherwise being propelled by the action of a wave, with or without use of a surfboard or other implement. Wave break area shall mean an area where ocean waves typically break.

389 Ibid.

390 Ibid.

391 See ibid.

392 Ibid.

${ }^{393}$ See Memorandum from Chief Lifeguard B Christmas Brewster, to City of San Diego Legislation Sponsorship Program (1999) (supporting the proposed Open Waves Act) (on file with author).

394 See Telephone Interview with Chris Brewster (14 November 2003).

395 See Memorandum from Chief Lifeguard B Christmas Brewster, to City of San Diego Legislation Sponsorship Program (1999) (supporting the proposed Open Waves Act) (on file with author).

396 See ibid.

397 See Telephone Interview with Chris Brewster (14 November 2003).

398 See ibid.

399 See ibid.

${ }^{400}$ See, for example, Telephone interview with Marcus Sanders (8 March 2004) (noting that 'most surfers hated the idea of the Open Waves Act'); Rielly, above n 151, 53 ('Government regulation won't work: neither is it desirable. The surf should always remain free of laws and the money-grabbing and overreaction of litigation.').

${ }^{401}$ See Surf Forum 2, above n 1, 322 (commentary by Rusty Miller); Surf Forum 1, above n 43, 233 (commentary by Justice Greg James). 
no business attempting to regulate the fishing industry., ${ }^{402}$ Similarly, many surfers believe that any regulation of surfing is an assault of their freedom. ${ }^{403}$ This cultural attitude makes the failure of the Waves Act unsurprising.

Surfers' hostility to regulation is also seen in their opposition to tort remedies for injuries sustained in the surf. Despite Australia's large and active population of surfers, tort actions brought by one surfer against another are extremely rare. In fact, in 2000 Professor Stanley Yeo claimed that 'in Australia there has never been a negligence action brought by one surfer against another surfer. ${ }^{404}$ Moreover, surfing organisations have actively campaigned against tort actions for surfing injuries. In Fluehr v City of Cape May, the New Jersey Supreme Court considered an award of damages to a plaintiff who was injured while body surfing. ${ }^{405}$ The plaintiff claimed that the city was liable for negligent supervision and failure to warn about the risks of the surf. ${ }^{406}$ The Surfers' Environmental Alliance-New Jersey and Surfrider Foundation both participated in the case as amici curiae and argued against liability. These amici were 'concerned that, as a result of the Appellate Division's decision [in favour of the plaintiff], municipalities will address the potential dangers of the ocean by restricting access to coastal waters, especially when the ocean is rough, thereby unduly limiting those who revel in the challenges presented by rough, breaking seas. ${ }^{, 407}$ Thus, surfers even see the tort system as a potential enemy of their freedom to access the waves.

The Waves Act was aimed at localism. It is also possible to imagine regulation aimed directly at controlling overcrowding. Given that extreme overcrowding can ruin surfing for everyone, it might seem that surfers would be better off allowing access to some of the most crowded breaks to be regulated. One option would be the use of a permit system similar to those used for popular hiking trails in national parks. I have found little discussion of such ideas. The discussion that exists is negative. For example, Justice Greg James bemoans 'the horrible thought that you might have to stand on the beach, along side one of those machines they have in the delicatessen, and take up a ticket with a number on and wait until your number comes up to be able to enter the water. ${ }^{408}$

Hostility to the idea of surfing permits is a component of surfers' hostility to any government regulation of surfing. Permits are likely to be particularly unattractive, however. First, a permit system could equalise access to the waves among locals and non-locals. Thus, permits would be disadvantageous to organised and close-

\footnotetext{
${ }^{402}$ Acheson, above, n 252, 260 (also noting that lobstermen believe that it is immoral to inform on another lobsterman').

${ }^{403}$ See Surf Forum 1, above n 43, 236 (commentary by Professor Stanley Yeo) (discussing an online forum about the regulation of surfing).

${ }^{404}$ Ibid 234; see also Brian Fitzgerald and Joanne Harrison, 'Law of the Surf' (2003) 77 Australian Law Journal 109, 114 (noting that although swimmers and body surfers have sued local municipalities for surf related injuries, 'there has not been a reported case of two surfers suing each other in a civil action'). 405 See Fluehr v City of Cape May, 732 A 2d 1035 (1999).

406 See ibid 1038

407 Ibid.

408 Surf Forum 1, above n 43, 233 (commentary by Justice Greg James).
} 
knit locals. The Bay Boys would find surfing permits even more threatening to their domination of Lunada Bay than the camera they defeated. Thus, opposition to permits from locals is likely to be fierce. If permits favoured locals (as parking permit systems often do) they may get more support from locals but they would likely encounter just as strong opposition from non-locals. ${ }^{409}$ Moreover, any permit system would be expensive to run and enforce, so the permits would probably involve a fee. A surfing fee of any kind would be very unattractive to most surfers who believe that surfing should be free. ${ }^{410}$

\section{CONCLUSION}

Sometimes surfers get along and sometimes they beat each other up. A complicated, cross-cultural set of cooperative norms helps ensure that the former is more common than the latter. Overall, surfing norms are a success story as they help millions of people share a valued resource that is usually left completely open to the public. Thus, surfing provides an excellent example of the power of extra-legal social norms to efficiently regulate public resources.

Despite the successes of surfing's cooperative norms, some surf breaks are dominated by surfers who practice exclusionary localism. These locals, like Acheson's lobster gangs, have carved little fiefdoms out of the public domain. Unlike the lobster gangs, however, these surf gangs cannot justify their actions on the basis of resource conservation. The surfers' commons is not subject to the same threat of permanent depletion so exclusionary localism should be seen as an unjustified appropriation of the public domain.

Exclusionary localism can even be violent and dangerous. Community groups and governments have tried to respond to this threat. Existing criminal law is not very effective at combating localism although it may be able to deter the most violent assaults associated with localism. Other legal responses, such as the proposed Open Waves Act, have been unsuccessful in the face of widespread surfer opposition to government regulation. This opposition means that private 'norm-reinforcement' and existing criminal law are the most productive tools to use against the worst elements of localism.

\footnotetext{
${ }^{409}$ For a discussion of similar issues relating to the allocation of public parking spaces see Richard E Epstein, 'The Allocation of the Commons: Parking on Public Roads' (2002) 31 Journal of Legal Studies 515, 536-538.

${ }^{410}$ See, for example, Surf Forum 1, above n 43, 236 (commentary by Professor Stanley Yeo).
} 